\title{
Ask, and tell as well: Question-Answer Clauses in American Sign Language
}

\author{
Ivano Caponigro $\cdot$ Kathryn Davidson
}

Published online: 7 May 2011

(C) The Author(s) 2011. This article is published with open access at Springerlink.com

\begin{abstract}
A construction is found in American Sign Language that we call a Question-Answer Clause. It is made of two parts: the first part looks like an interrogative clause conveying a question, while the second part resembles a declarative clause answering that question. The very same signer has to sign both, the entire construction is interpreted as truth-conditionally equivalent to a declarative sentence, and it can be uttered only under certain discourse conditions. These and other properties of Question-Answer Clauses are discussed, and a detailed syntactic, semantic, and pragmatic account is provided. Question-Answer Clauses are argued to be copular clauses consisting of a silent copula of identity connecting an interrogative clause in the precopular position with a declarative clause in the postcopular position. Pragmatically, they instantiate a topic/comment structure, with the first part expressing a sub-question under discussion and the second part expressing the answer to that sub-question. Broader implications of the analysis are discussed for the Question Under Discussion theory of discourse structuring, for the analysis of pseudoclefts in spoken languages, and for recent proposals about the need for answerhood operators and exhaustivity operators in the grammar and the consequences for the syntax/semantics/pragmatics interface.
\end{abstract}

Keywords American Sign Language - Question - Copular clause · Pseudocleft · Exhaustivity · Question Under Discussion Theory

\section{Introduction}

In American Sign Language (ASL), a construction is found that consists of two parts: the first part looks like an interrogative clause conveying a question, while the

I. Caponigro $(\bowtie) \cdot K$. Davidson

Linguistics Department, University of California, San Diego, 9500 Gilman Dr.,

La Jolla, CA 92093, USA

e-mail: ivano@ucsd.edu 
second part resembles a declarative clause or a smaller constituent conveying the/an answer to that question. We label the first part the $Q$ (uestion)-constituent, the second part the A(nswer)-constituent, and the entire construction a Question-Answer Clause ( $Q A C)$. The two parts of a QAC cannot be separated in any way, nor can they be flipped; the very same signer has to sign both; and the entire QAC is interpreted as truth-conditionally equivalent to a declarative sentence and cannot be signed out of the blue.

In this paper, we provide a detailed syntactic, semantic, and pragmatic analysis of QACs. We argue that a QAC is a declarative copular clause consisting of a silent copula connecting an embedded interrogative clause in the precopular position (the Q-constituent) and an embedded declarative clause in the postcopular position (the A-constituent). Semantically, a QAC is an identity statement between the denotation of the Q-constituent and the denotation of the A-constituent. Pragmatically, a QAC instantiates a topic/comment structure, with the Q-constituent expressing the topic as picking out a sub-question under discussion and the A-constituent expressing the comment as the answer to that sub-question.

Besides contributing to a better understanding of QACs and ASL, our analysis has at least three broader implications. First, QACs show that two syntactically and semantically independent linguistic objects like an interrogative clause and a declarative clause, which form a unit usually only at the discourse level as a question-answer pair, can be realized as a syntactic and semantic unit as well. A similar analysis has already been advocated for specificational pseudoclefts crosslinguistically (Ross 1972; den Dikken et al. 2000; Schlenker 2003), although objections have been raised because of syntactic and semantic differences with actual question-answer pairs. We show that QACs in ASL, unlike pseudoclefts, do indeed pattern like question-answer pairs in both their syntax and semantics.

Second, our analysis of QACs brings further evidence in favor of the need for answerhood operators and exhaustivity operators in the grammar. Heim (1994) and subsequent related work (Dayal 1996; Beck and Rullmann 1999; Lahiri 2002; Romero 2007, a.o.) have argued that answerhood operators are needed to account for the semantic properties of embedded interrogative clauses and other constructions. Our semantic analysis of QACs crucially requires the same answerhood operators for the correct interpretation of the Q-constituent. A recent proposal about the syntax/semantics/pragmatics interface by Chierchia et al. (2009, to appear) argues that the grammar makes available a silent operator that is responsible for exhaustivity in scalar implicatures. Exhaustivity is observed in the interpretation of the A-constituent of a QAC as well. Since the A-constituent is embedded within the QAC, no discourse-level pragmatic principles can be invoked to justify exhaustivity, unlike what has been suggested for declarative clauses or smaller constituents used to answer matrix constituent interrogatives. On the other hand, we argue that the exhaustivity operator in Chierchia et al. (2009, to appear) and, more generally, their view of the syntax/semantics/pragmatics interface can account for the patterns seen in QACs.

Finally, our analysis supports a model of discourse structuring along the line of the Question Under Discussion theory (Roberts 1998; Büring 2003) by showing that the pragmatic properties of QACs can be captured if QACs are analyzed as a single 
sentence conveying both a sub-question under discussion (Q-constituent) and its answer (A-constituent).

The paper is structured as follows. Section 2 briefly describes the main features of ASL that will be relevant for our discussion of QACs. Section 3 introduces QACs, presents our proposal informally and provides several supporting arguments. Section 4 turns our proposal into a precise syntactic-semantic analysis. Section 5 discusses the main pragmatic properties of QACs and suggests an account within the Question Under Discussion theory of discourse modeling. Section 6 compares QACs to specificational pseudoclefts to conclude that the two constructions are not the same, unlike what has been suggested previously. Finally, Section 7 concludes with some general remarks and open issues.

\section{ASL Background}

\subsection{ASL data}

ASL is the primary language of the Deaf and hard of hearing community in the United States and most of Canada. In the 1960s, pioneering research by Stokoe et al. (1976) and Klima and Bellugi (1979) laid the foundations of a large body of work showing that, in terms of linguistic structure and language processing, ASL patterns like spoken languages and should be considered a natural language.

ASL is a language produced through movements of parts of the body and perceived through the visual system. Meaningful movements can be divided into two categories: manual signs (produced using the hands) and non-manual movements (produced with the rest of the body and head). Manual signs are made of smaller parts (movements, locations, and handshapes) that have internal structure governed by phonological rules, and are themselves analogous to morphemes and words in spoken languages. Manual signs also carry much of the lexical semantic content of a sentence. Non-manual movements are discussed in more detail in Sect. 2.3 below. The word order that is generally accepted as most basic in ASL is Subject-VerbObject. However, word order is very sensitive to the discourse context and it is common to organize a sentence using a topic-comment structure which may alter the basic word order. We refer the reader to Sandler and Lillo-Martin (2006) for a comprehensive overview of the main features of ASL.

In this paper, we present original data collected at various points from four signers of ASL between the ages of 25 and 55 using standard linguistic elicitation techniques. Two of the four consultants were deaf, two were hearing, and all were native signers, which we defined as having been exposed from birth to ASL as the first, and primary, means of communication among immediate family members. All had mothers and fathers who were both deaf and who used ASL (not a signed form of English) in the home. Although this is not necessarily the case, both of our hearing consultants consider themselves dominant in ASL, as they both spend the majority of their professional and social time within the deaf community. Data that are not presented as original data in this paper are taken from the sources cited, and to the best of our knowledge were also obtained from native, typically deaf, signers of ASL. 


\subsection{Transferring a visual language to paper}

Following convention extending back at least to Klima and Bellugi (1979), we will write manual signs in capital letters, using rough English glosses. This addresses the issue of transferring hand and body movement to paper by immediately glossing the signs in English. For example, Fig. 1 shows a still of a video of a woman producing the sign that would be translated as car. We will note this word first with the English gloss in capital letters, to indicate which sign was used, and then give the English translation, which in the case of a single sign is the same as the gloss.

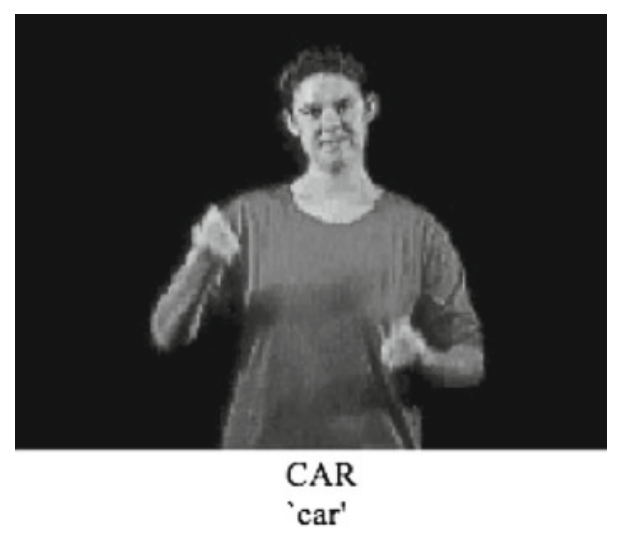

Fig. 1 Image from American Sign Language Linguistic Research Project (2007)

\section{(1) CAR \\ 'car'}

This glossing convention applies to the manual signs that constitute much of the lexicon of ASL. Other body and facial movements that are part of the grammar are discussed in the next section. In some areas we simplify to aid readability. For instance, pointing indexicals in ASL, while unique to sign languages, can correspond to either pronouns or demonstratives in English; as this distinction is not relevant to our investigation, we avoid the issue of the exact semantics of such signs by glossing them using their closest English translation within the given context (e.g. $H E$ or THAT).

\subsection{Non-manual marking}

The linguistic information in ASL that does not come from signs produced with the hands is referred to as non-manual marking. The relationship between non-manual marking and manual signs in ASL has frequently been compared to the relationship between intonation and spoken words in spoken languages (see Wilbur 1999 for empirical evidence). Just as intonation is conveyed simultaneously with words, so is non-manual marking concurrent with manual signs. Furthermore, in spoken 
languages two sentences with the same sequence of spoken words but different intonation can have different meanings, as is the case with rising and falling declaratives in English (Gunlogson 2003) and declaratives and polar interrogatives in Italian. So too in sign languages may non-manual marking affect the reading of a sentence.

One major area in which we can see the importance of non-manual marking in ASL is in matrix constituent and polar interrogatives. Both have obligatory nonmanual marking associated with them. Since both constructions are relevant for what follows, we will take a moment to show how each works, and in the process illustrate how we will notate non-manual marking.

\subsection{Interrogative clauses in ASL}

Matrix polar interrogatives in ASL look identical to the corresponding declaratives in word order, but differ in non-manual marking. To illustrate, in Fig. 2 we give an example of a declarative sentence in ASL. This sentence consists of a sequence of four manual signs: JOHN WANT SELL CAR. It is transcribed as in (2).

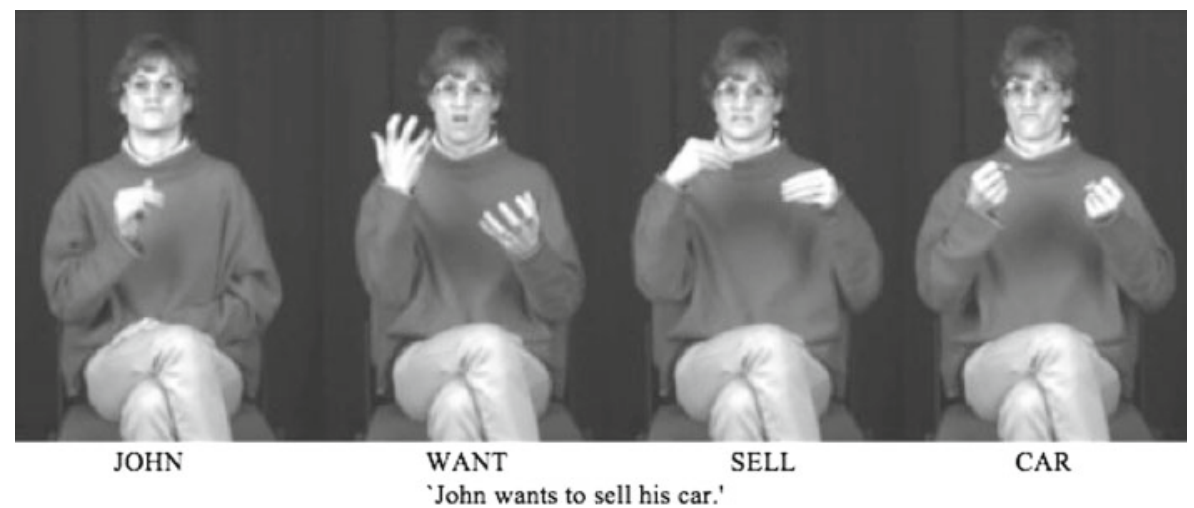

Fig. 2 Declarative clause. Images from American Sign Language Linguistic Research Project (2007)

\section{(2) JOHN WANT SELL CAR. \\ 'John wants to sell (his) car.'}

Now, consider the polar interrogative in Fig. 3. The interrogative as well consists of a sequence of four manual signs, THAT HER FATHER CAR, but in the interrogative the signer also has her eyebrows raised, which can be seen by comparing it to the declarative in Fig. 2. Following convention, we note non-manual marking above the glosses for the manual signs (Baker-Shenk 1983). The abbreviation notes the type of the non-manual marking, while the extension of the line indicates its duration. For example, the sentence in Fig. 3 has brow raising non-manual marking (br) throughout and is transcribed as in (3) below (contrasted with the declarative sentence in (2)). Brow raising is the obligatory non-manual marking in polar interrogatives. 


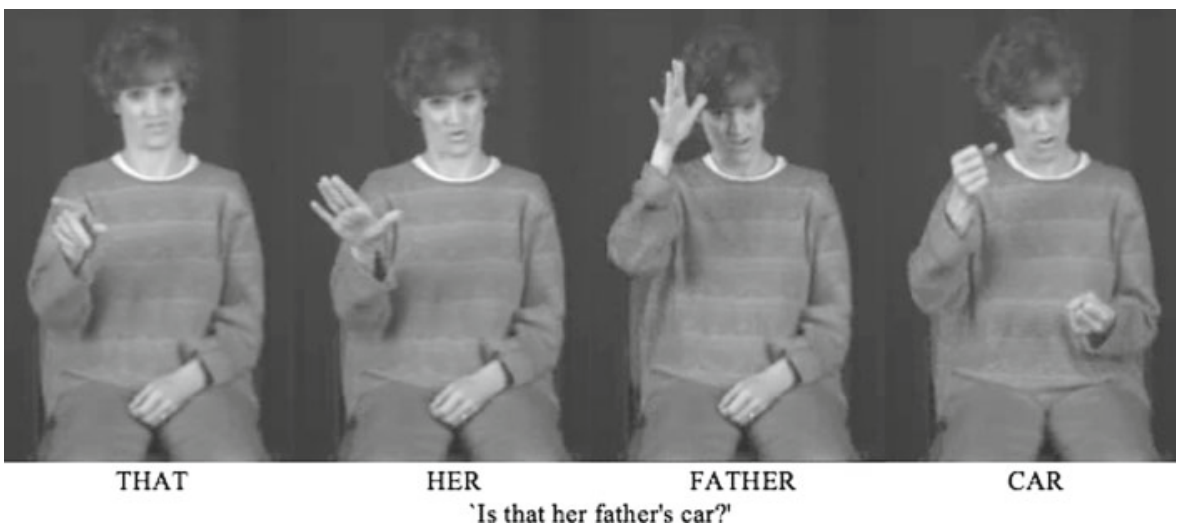

Fig. 3 Polar interrogative clause. Images from American Sign Language Linguistic Research Project (2007) $b r$

THAT HER FATHER CAR?

'Is that her father's car?'

In contrast to the brow raising seen in matrix polar interrogatives, the non-manual marking on matrix constituent interrogatives in ASL is brow furrowing (bf). This can be seen in the example in Fig. 4, which is transcribed as in (4) below.

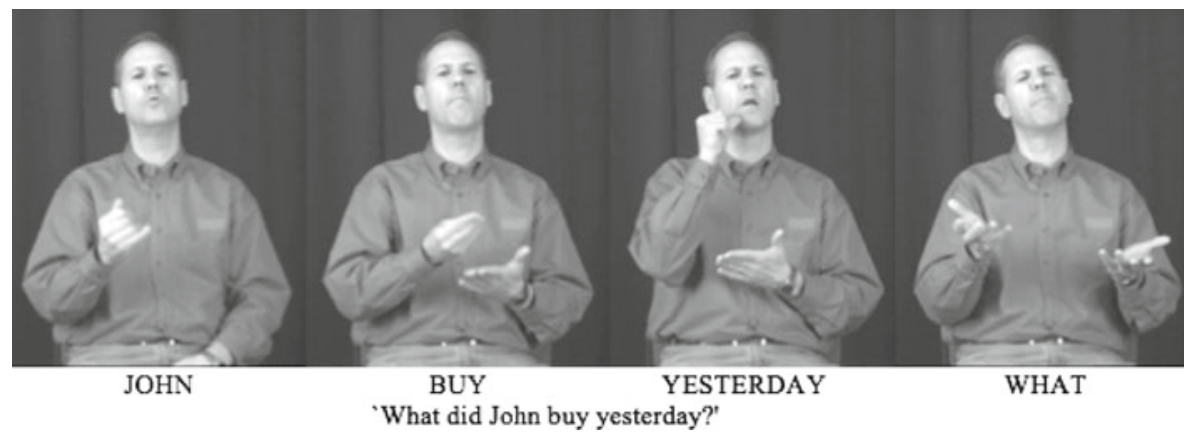

Fig. 4 Constituent interrogative clause. Images from American Sign Language Linguistic Research Project (2007)

(4) bf

JOHN BUY YESTERDAY WHAT?

'What did John buy yesterday?'

There are restrictions on the extension of non-manual marking in constituent interrogatives: it must always appear on the wh-word itself and at the end of the 
interrogative clause, but can sometimes be omitted at the beginning, as in (4). ${ }^{1} \mathrm{We}$ will not go further into that issue here, but we refer the reader to Petronio and LilloMartin (1997) and Neidle et al. (2000) for discussion on this topic and wh-interrogatives in ASL more generally. We have also simplified above and in what follows by using $b r$ and $b f$ to stand in for collections of non-manual movements associated with polar interrogatives and constituent interrogatives, respectively, of which the raising and the furrowing of the eyebrows are only the most prominent features.

Along with playing an important role in interrogative clauses, non-manual marking has been argued to mark topicalization, conditionals, relative clauses, verb agreement, etc. For these reasons, non-manual marking in ASL-as in many other sign languages - should be considered to play at least as great a role as intonation in spoken languages. However, like intonation in English, it will not be marked in our examples below unless it is relevant to the issue at hand.

\section{Introducing Question-Answer Clauses}

We can now take a closer look at the construction that this paper focuses on: QACs. Recall that QACs are strings signed by the same signer with a first part, the Q-constituent, that looks like an interrogative clause conveying a question and the remainder, the A-constituent, that looks like a declarative clause (or a smaller constituent) conveying the/an answer to the question. An example can be seen in Fig. 5, where the first three frames are part of the Q-constituent (JOHN BUY WHAT) and the last frame is part of the A-constituent $(B O O K)$.

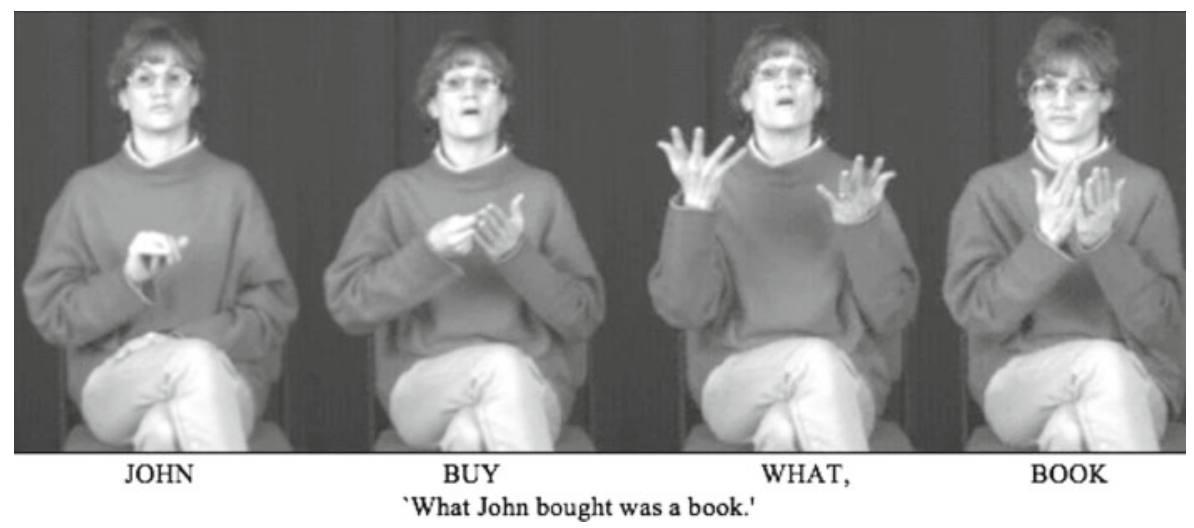

Fig. 5 Constituent QAC. Images froms American Sign Language Linguistic Research Project (2007)

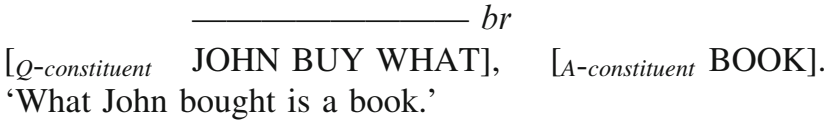

\footnotetext{
1 ASL does not allow for multiple wh-interrogative clauses: a constituent interrogative clause in ASL can contain only one wh-word (a pattern attested in spoken languages as well, e.g., in Italian).
} 
The Q-constituent can be distinguished from the A-constituent by non-manual marking, which is obligatory brow raising in the Q-constituent. This brow raising cannot carry over to the A-constituent. We transcribe this as in (5), where we follow Petronio (1991) in placing a comma between the Q-constituent and the A-constituent to aid readability.

The Q-constituent of the QAC in (5) above contains a wh-phrase and looks like a constituent interrogative. We call this kind of QAC a constituent QAC. However, it is also possible to have a QAC with a Q-constituent without a wh-phrase that looks like a polar interrogative, as shown in Fig. 6 and its transcription in (6). We call the latter kind of QAC a polar QAC. We will examine both constituent and polar QACs in this paper.

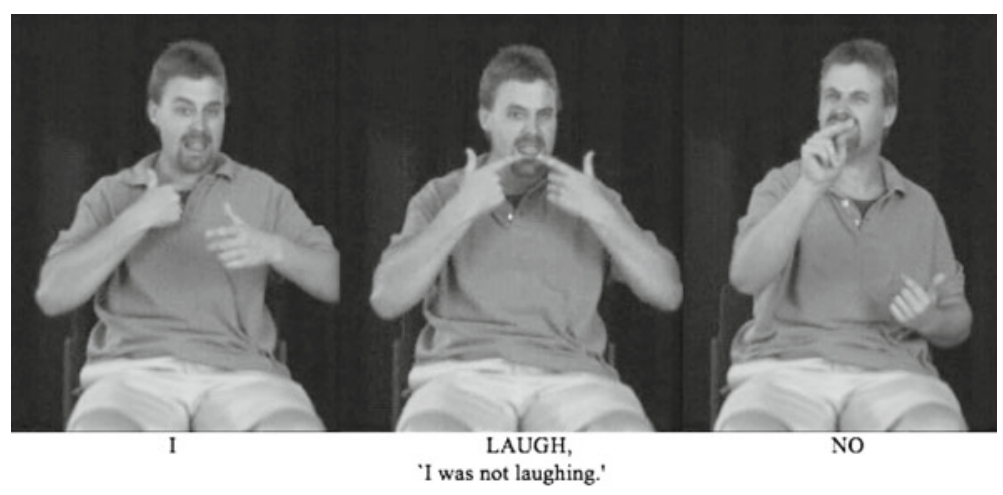

Fig. 6 Polar QAC. Images from American Sign Language Linguistic Research Project (2007)

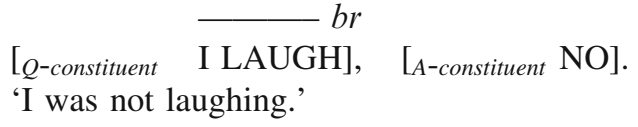

QACs are sometimes referred to in the ASL community as 'rhetorical questions,' which we think highlights the intuition that there is an interrogative component, and that this interrogative component is not information-seeking. In fact, both of these aspects of signers' intuitions have correlates in our analysis of QACs, which we summarize in $(7){ }^{2}$

\section{(7) Our claims about the nature of QACs:}

1. The Q-constituent of a QAC looks like an interrogative clause because it is an embedded interrogative clause.

2. The A-constituent looks like a declarative clause because it is an embedded declarative clause.

\footnotetext{
${ }^{2}$ Our analysis will make clear how QACs differ from true rhetorical questions (e.g. "After all, is the Pope Catholic?"), which are not used to convey new information, since they are naturally uttered when both the speaker and crucially the addressee already know the answer to the question. Also, unlike QACs, rhetorical questions are often uttered without being followed by their answer (see Caponigro and Sprouse 2007).
} 
3. Native signers' intuition that QACs are not information-seeking but function as statements (as highlighted by our translations) derives from the fact that QACs are syntactically and semantically single declarative clauses.

4. The Q-constituent of a QAC conveys a question and the A-constituent of the same QAC conveys a true answer to that question.

In what follows, we provide several arguments in favor of each of these claims.

\subsection{The Q-constituent as an interrogative clause}

In this section, we present arguments supporting the first claim in (7), that the Q-constituent in QACs is an embedded interrogative clause. First, we show that the Q-constituent looks like an interrogative clause (Sect. 3.1.1). Second, we show that the range of wh-words that can occur in the Q-constituent is the same as in constituent interrogatives (Sect. 3.1.2). Third, we show that ASL does not have any other constructions that make use of wh-words, except for constituent interrogatives and QACs (Sect. 3.1.3). In particular, headed relative clauses in ASL do not allow for wh-words, and wh-words in headless free relatives are also not attested in ASL. Finally, we bring evidence in favor of the claim that the Q-constituent is an embedded interrogative rather than a matrix one. We show that the doubling of wh-words is allowed in matrix interrogatives, but not in embedded ones, and that QACs pattern like the latter (Sect. 3.1.4). Moreover, there are differences in nonmanual marking between matrix constituent interrogatives of any kind and the Q-constituent, further supporting the notion of the Q-constituent as an embedded, not matrix, interrogative (Sect. 3.1.5).

\subsubsection{Argument 1: The Q-constituent looks like an interrogative clause}

A first piece of evidence that the Q-constituent is an interrogative clause is that the surface string of the Q-constituent is the same string as an interrogative clause (Hoza et al. 1997). For example, the bracketed Q-constituent of the QAC in (8) is identical to the constituent interrogative in (9).

[JOHN BUY YESTERDAY WHAT], BOOK.

'What John bought yesterday was a book.'

(9) JOHN BUY YESTERDAY WHAT?

'What did John buy yesterday?'

Similarly, the bracketed Q-constituent of the QAC in (10) is identical to the polar interrogative in (11).

(10) [JOHN HAVE MOTORCYCLE], NO.

'John doesn't have a motorcycle.'

(11) JOHN HAVE MOTORCYCLE? 
'Does John have a motorcycle?'

The similarities above are the first piece of evidence that leads us to conclude that the Q-constituent is an interrogative clause.

\subsubsection{Argument 2: Range of wh-words}

The range of wh-words that can occur in the Q-constituent of QACs is the same as in constituent interrogatives. Examples of QACs with some of the wh-words that are found in ASL are given in (12)-(20) below. The very same wh-words can also occur in constituent interrogatives. We have not found any wh-word that can appear in an interrogative but not in a QAC, or vice-versa.

(12) JOHN EAT WHAT, PASTA.

'What John ate was pasta.'

(13) GO-TO PARTY WHO, JOHN.

'The person that went to the party was John.'

(14) LEAVE MY SHOES WHERE, KITCHEN. (Wilbur 1994: ex. 4)

'The place where I left my shoes was the kitchen.'

(15) JOHN COOK WHEN, YESTERDAY.

'Yesterday was when John cooked.'

(16) BABY CRY WHY, MOTHER LEAVE.

'The baby cried because its mother left.'

(17) JOHN LIKE GIRL WHICH, MARY.

'The girl that John likes is Mary.'

(18) JOHN READ HOW, VERY-FAST.

'John read very fast.'

(19) CAR COST HOW-MUCH, \$20,000.

'The car cost $\$ 20,000$.'

(20) TOMORROW DO-DO, GO-TO MOVIE.

'What we'll do tomorrow is go to the movies.'

If the Q-constituent is an interrogative clause, then it is unsurprising that the very same wh-words appear in both.

3.1.3 Argument 3: No wh-words in other constructions 
ASL does not have any other constructions, besides constituent interrogatives and QACs, that make use of wh-words. This contrasts with many languages in which wh-words occur in headless and/or headed relative clauses or in pseudo-cleft clauses. For instance, in English wh-words can be used in a headless/free relative like the bracketed string in (21), as well as in a headed relative like the bracketed string in (22) and in the pseudo-cleft in (23).

(21) I like [what John bought.]

(22) I called the people [who Mary likes.]

(23) [What John bought] was Lolita.

However, in ASL, what would be the corresponding headless free relative, (24), or headed relative, (25), are ungrammatical, if anything feeling like a signed version of English (Liddell 1978). In Section 6, we discuss at length why QACs are not pseudoclefts.

* I LIKE [WHAT JOHN BUY]/[JOHN BUY WHAT]. ('I like what John bought.')

* I CALL PEOPLE [WHO MARY LIKE]/[MARY LIKE WHO]. ('I called the people who Mary likes.')

In short, there is no evidence for the use of wh-words outside of interrogatives in ASL. We take this conclusion as strengthening our claim that the Q-constituent is an interrogative clause.

\subsubsection{Argument 4: Doubling of wh-words}

The three arguments we just presented show that the Q-constituent of a QAC is an interrogative clause, one which could be either matrix or embedded. To distinguish between these two possibilities, we can apply our knowledge of at least two ways in which embedded interrogatives differ from matrix interrogatives in ASL. One is that matrix interrogatives allow wh-words in situ and at the end of the interrogative clause, as in (26), while this doubling of wh-words is ungrammatical in embedded interrogatives, like (27). What we find is that the Q-constituent of QACs also does not allow doubling of wh-words, as shown in (28).

(26) JOHN BUY WHAT YESTERDAY WHAT?

'What did John buy yesterday?'

*HE ASK JOHN BUY WHAT YESTERDAY WHAT?

('He asked what John bought yesterday.') 
*JOHN BUY WHAT YESTERDAY WHAT, BOOK.

('What John bought yesterday was a book.')

This is suggests an analysis of the Q-constituent as an embedded, rather than matrix, interrogative.

\subsubsection{Argument 5: Non-manual marking}

The second difference between matrix interrogatives and embedded interrogatives is in the non-manual marking that appears with each. Recall from Sect. 2.4 that in ASL both matrix polar interrogatives and matrix constituent interrogatives have obligatory associated non-manual marking. Matrix polar interrogatives require brow raising (br), while matrix constituent interrogatives require brow furrowing (bf). Embedded polar or constituent interrogative interrogatives, by contrast, do not have a fixed obligatory non-manual marking that distinguishes them from each other or from other embedded structures. Rather, their non-manual marking varies according to the predicate under which they are embedded (Petronio and Lillo-Martin 1997). ${ }^{3}$ A summary can be found in Table 1 .

As highlighted in the table, the non-manual marking on the Q-constituent of a QAC is not the same as in the corresponding matrix interrogative. The Q-constituent

Table 1 Non-manual marking in different types of constructions in ASL

\begin{tabular}{|l|l|}
\hline CONSTRUCTION & NON-MANUAL MARKING \\
\hline Matrix declarative clause & Neutral \\
\hline Matrix constituent interrogative clause & Brow furrowing \\
\hline $\begin{array}{l}\text { Matrix polar interrogative clause } \\
\text { Topicalized constituent } \\
\text { Q-constituent of a QAC }\end{array}$ & Brow raising \\
\hline Embedded (constituent/polar) interrogative clause & Varies with the embedding predicate \\
\hline
\end{tabular}

of a (constituent) QAC always requires brow raising, while matrix constituent interrogatives always require brow furrowing. We suggest that the non-manual marking pattern of the Q-constituent of QACs resembles that of embedded interrogatives in depending on the embedding predicate. As we argue in the next section, a silent copula connects the two main constituents of any QAC and-we sug-

\footnotetext{
${ }^{3}$ Embedded interrogatives-especially polar interrogatives-are not common in ASL. Signers much prefer the direct quotation of a matrix constituent interrogative (e.g., the ASL equivalent of the English She wonders: "Who ate the quiche?') to the corresponding embedded construction (e.g., She wonders who ate the quiche), and, even more strongly, the direct quotation of a matrix polar interrogative (e.g., She wonders: 'Did he eat the quiche?') to the corresponding embedded structure (e.g., She wonders if he ate the quiche).
} 
gest-triggers the same constant non-manual marking on the Q-constituent, whether a constituent or a polar interrogative.

It might be thought that the reason why QACs have different non-manual marking than matrix interrogatives is because they serve a different discourse function. A matrix interrogative is usually information seeking, but in a QAC the signer clearly already knows the answer and is not seeking information. However, in ASL the non-manual marking pattern for matrix interrogatives is always the same: brow furrowing for matrix constituent interrogatives and brow raising for matrix polar interrogatives. It does not make any difference whether the matrix interrogatives are interpreted as information seeking, as in (29)-(30), echo questions, as in (31)-(32), or true rhetorical questions, as in (33)-(34), as discussed in Wilbur (1994). All matrix interrogatives are signed with the same non-manual marking, whether information seeking or not. Therefore, the change in non-manual marking in Q-constituents of QACs is unexpected if they are matrix interrogatives.

JOHN BUY WHAT?

'What did John buy?'

JOHN BUY CAR?

'Did John buy a car?'

$$
\begin{array}{ll}
\text { Signer } A: & \begin{array}{l}
\text { KEYS, SEE WHERE? } \\
\text { 'Where are my keys?' }
\end{array}
\end{array}
$$

Signer A: KEYS, SEE WHERE? (Wilbur 1994: Ex. 3)

Signer B: SEE WHERE?

'Where are your keys? I think they're in the kitchen.'

\section{Signer $A$ : CLEAN HOUSE YOU?}

'Will you clean the house?'

\section{Signer B: CLEAN HOUSE I? TOMORROW WILL. \\ 'Will I clean the house? Sure, tomorrow I will (clean it).'}

(33) Scenario: Two signers know John very well, including where he is from, and one signer wants to signal that John should know something, given where he is from; therefore, she signs:

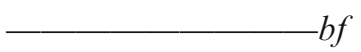

JOHN FROM WHERE?

'[After all,] where is John from?' 
(34) Scenario: Two deaf signers know each other very well, and one signer wants to make a joke that the other should have known something because of her deafness; therefore, she signs:

$-b r$

YOU DEAF YOU?

'[After all,] aren't you deaf?'

To summarize, we have presented several arguments supporting the proposal that the Q-constituent of a QAC is an embedded interrogative clause. Next, we show that the A-constituent is a declarative clause.

\subsection{The A-constituent as a declarative clause}

In this section, we provide evidence to support our second claim in (7), namely, that the A-constituent of a QAC is an embedded declarative. At the surface, the A-constituent often looks like a constituent smaller than a clause. Nevertheless, it can always optionally be a full declarative clause without any change in meaning. This can be seen in the A-constituent of the QAC in (35), whose Q-constituent is a constituent interrogative, and in the A-constituent of the QAC in (36), whose Q-constituent is a polar interrogative. br

JOHN BUY WHAT, (HE BUY) BOOK.

'What John bought was a book.'

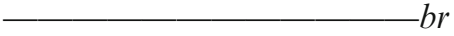

JOHN HAVE MOTORCYCLE, NO (HE NOT HAVE MOTORCYCLE). 'John doesn't have a motorcycle.'

What is optionally omitted is constrained such that the new information (e.g., $B O O K$ in (35)) is obligatorily overt, while the information that appeared in the Q-constituent (e.g., HE BUY in (35)) may be omitted or, as we suggest, covert in the A-constituent. This pattern is identical to what is observed in discourse-level question-answer pairs, which further supports our general hypothesis about QACs as consisting of an interrogative clause conveying a question and a declarative clause conveying the answer to that question.

So far we have only shown evidence that the A-constituent is a declarative clause. But our initial claim was stronger: the A-constituent is an embedded declarative clause. Unfortunately, there is no simple way to distinguish a matrix declarative from a tensed embedded declarative in ASL (e.g., ASL does not have a complementizer like English that or any consistent marking of embedding on the embedded predicate). In the next section, we show that the entire QAC can be embedded, which implies that the A-constituent is able to be embedded too, as part of a QAC. Later, when we discuss our semantic analysis (Sect. 4), we bring evidence that the Q-constituent cannot be a leftdislocated topic with the A-constituent being the matrix clause. 
3.3 The QAC as a single declarative clause

Let's now turn to the evidence in favor of our third claim in (7), that a QAC is a single declarative clause. We support this claim by showing that the entire QAC can be embedded as the complement of predicates that normally take only a declarative clause as their complement. Example (37) shows that a QAC can occur as the complement of such verbs. ${ }^{4}$

\section{THOSE GIRLS HOPE/THINK [THEIR FATHER BUY WHAT, CAR].} 'Those girls hoped/thought that what their father bought was a car.'

Predicates such as HOPE or THINK select for a declarative clause as their complement, as shown in (38), while they do not allow for an interrogative clause, as shown in (39).

(38) THOSE GIRLS HOPE/THINK [THEIR FATHER BUY CAR].

'Those girls hoped/thought that their father bought a car.'

\section{*THOSE GIRLS HOPE/THINK [THEIR FATHER BUY WHAT].}

Predicates such as $A S K$ only take interrogative complements, as shown in (40). They are unacceptable if a QAC occurs as their complement, as shown in (41).

(40) THOSE GIRLS ASK [WHAT THEIR FATHER BUY]/ *[THEIR FATHER BUY CAR].

'Those girls asked $\{$ what their father bought $\} / *\{$ that their father bought a car $\}$.'

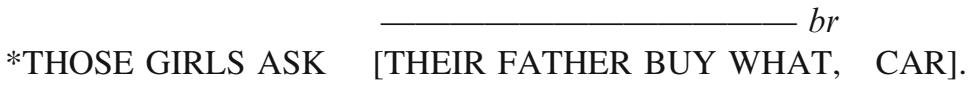

If the entire QAC can be embedded only under predicates which take declarative clauses as complements, then the entire QAC must have the syntax and semantics of a declarative clause.

\footnotetext{
${ }^{4}$ The extension of the non-manual marking in (37) is important to this example, as the same string of signs with different non-manual marking can also appear as a matrix QAC, as shown in (i) below.

(i) $-b r$

[THOSE GIRLS HOPE THEIR FATHER BUY WHAT], CAR.

'What those girls hope their father bought was a car.'

In (i) the Q-constituent is the entire bracketed bi-clausal phrase.
} 
To further show that the entire sentence in (37) is a single clause, we can apply the test for embedded clauses in ASL suggested in Padden (1988). In ASL, subjects or main verbs may be doubled at the end of their own clause, but not outside it. Therefore, doubling of subjects or main verbs can be taken as a marker of clause boundaries. Our consultants report sentences such as (42)-(43) with a QAC following the matrix clause and preceding the doubled element to be acceptable, without a sizable pause between $C A R$ and THEY/HOPE. This indicates that the QAC is fully part of the larger matrix clause and, therefore, is embedded.

\section{br}

THOSE GIRLS HOPE [THEIR FATHER BUY WHAT, CAR] THEY. 'Those girls hoped that what their father bought was a car.'

THOSE GIRLS HOPE. [THEIR FATHER BUY WHAT, CAR] HOPE. 'Those girls hoped that what their father bought was a car.'

Notice that the examples we just discussed are not examples of reported or quoted speech, akin to (44) in English.

(44) They girls hope, "What our father bought was a car!"

Another piece of evidence in favor of the embedded status of the QACs in (37), (42), and (43) is the coreference pattern between the matrix subject and a possessive pronoun in the embedded subject. The example in (45) —identical to (36), including the non-manual marking on the QAC ${ }^{5}$ — shows that the 3rd plural possessive THEIR within the QAC can corefer with the matrix subject THOSE GIRLS, while the 1st plural possessive OUR cannot. This is the same pattern that is observed with truly embedded possessives in English, as shown in (46). On the other hand, quoted speech exhibits exactly the opposite pattern, as shown in (47).

[THOSE GIRLS $]_{m}$ HOPE

[THEIR ${ }_{m} /$ OUR $_{* m}$ FATHER BUY WHAT, CAR].

'Those girls hoped that what our father bought was a car.'

(46) [Those girls $]_{m}$ hope that what their ${ }_{m} /$ our $_{* m}$ father bought was a car!

(47) [Those girls $]_{m}$ hope, "What their ${ }_{* m} /$ our $_{m}$ father bought was a car!"

Finally, if the QAC were not a unit and its Q-constituent and the A-constituent were two independent clauses, it should be possible to have a hedge between the two

\footnotetext{
5 In ASL, direct quotation typically co-occurs with a combination of non-manual/body movements to indicate the new speaker ("role shift"), but our consultants agree that there is no special role shifting marking on (37), (42), and (43).
} 
constituents, as between a discourse-level question-answer pair; see (48). Our consultants do not find this option acceptable for QACs, as shown in (49).

Q: COME-TO PARTY WHO? A: I THINK LAURA (COME-TO PARTY).

Q: 'Who came to the party?' A: 'I think it was Laura.'

\section{$b r$}

*COME-TO PARTY WHO, I THINK LAURA (COME-TO PARTY).

('I think it was Laura who came to the party.')

The indivisibility of the two parts of the QAC on their own, as well as the behavior of the entire QAC when embedded in a larger clause, all point to an analysis of the QAC as a single clause.

\subsection{QACs as question-answer pairs}

Finally, let's consider the fourth and last claim in (7): the meaning relationship between the Q-constituent and the A-constituent of a QAC is always such that the Q-constituent conveys a question and the A-constituent conveys the/a true answer to that question. First, every QAC can straightforwardly be turned into a discourselevel question-answer pair. For instance, the Q-constituent in the QAC in (50) looks identical to the matrix interrogative in the discourse-level question-answer pair in (51), while the A-constituent is identical to the discourse-level answer constituent. Notice that in both constructions, the "answer" can be short or long, as signaled by the optional material in parentheses.

(50) JOHN LIKE GIRL WHICH, (HE LIKE) MARY.

'The girl that John likes is Mary.'

\section{Signer $A$ : JOHN LIKE GIRL WHICH? \\ 'Which girl does John like?' \\ Signer B: (HE LIKE) MARY. \\ '(He likes) Mary.'}

Also, both constructions pattern the same with respect to exhaustivity, as we will discuss in Sect. 4.3, and share several pragmatic properties, as we will discuss in Sect. 5 .

\subsection{Previous analyses of QACs}

Previous analyses of QACs can be divided basically into two main groups. Hoza et al. (1997) argue that QACs are made of a matrix interrogative and a matrix declarative and form a question-answer pair at the discourse level only. This claim is untenable in light of the data we have discussed above. Section 3.1 showed that the Q-constituent 
patterns more like an embedded than a matrix interrogative, while Sect. 3.3 showed that a QAC is a declarative clause and therefore forms a syntactic and semantic unit.

Following Petronio (1991), Wilbur $(1994,1996)$ proposes a different approach to QACs. Like us, she argues that QACs form a syntactic and semantic unit. But, unlike us, she claims that QACs are the ASL equivalent of pseudoclefts in spoken languages. In particular, she argues that what we have labeled the Q-constituent and analyzed as an interrogative clause is, instead, a headless relative clause conveying old information, while our A-constituent is not a declarative clause in her analysis, but a smaller constituent conveying new information. Although we agree that the whole QAC is a declarative clause, we disagree on the internal structure that Wilbur assigns to a QAC. In Sect. 3.1, we presented several arguments showing that the Q-constituent of a QAC is actually an embedded interrogative and crucially not a relative clause, and in Sect. 3.2 we argued that the A-constituent is a (partially elided) declarative clause. In particular, as already mentioned, there is no independent evidence that wh-words can ever be used to form any kind of relative construction in ASL. Finally, as noted in Hoza et al (1997), Wilbur's proposal cannot handle QACs with a polar interrogative as the Q-constituent, because there is no way to analyze their Q-constituent as a relative clause and their A-constituent as a non-clausal constituent. We will compare QACs to pseudoclefts in spoken languages in detail in Sect. 6 to further highlight the crucial differences between the two constructions.

\section{The semantics of QACs}

In the previous section we presented several arguments showing that the entire QAC is either a matrix or embedded declarative clause, while its Q-constituent and A-constituent are both embedded clauses, the former an interrogative and the latter a declarative. The Q-constituent conveys a question and the A-constituent conveys the/a true answer to that question. In this section, we propose a fully compositional semantic analysis for QACs. We first argue for a syntactic structure that makes QACs identical to copular sentences (Sect. 4.1). Then, we propose a preliminary semantic analysis for QACs (Sect. 4.2). The discussion of new data about the semantic behavior of QACs concerning exhaustivity (Sect. 4.3) motivates a revised semantic analysis (Sect. 4.4).

\subsection{Syntactic analysis}

We propose that syntactically a QAC is a declarative clause (IP) with a silent copula $e_{B E}$ taking an interrogative $\mathrm{CP}$ (the Q-constituent) as its subject and an IP with possibly elided material (the A-constituent) as its complement, as shown in (52). We assume a VP-internal position for the subject of QACs for lack of counterevidence, but we are noncommittal about the existence of more than one functional level above the VP in QACs. 
(52)

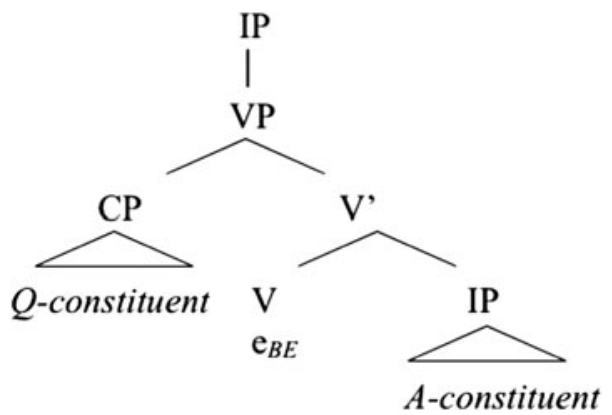

The syntactic structure in (52) accounts for the embedded-like behavior of the Q-constituent and the A-constituent, since they are analyzed as the two arguments of the silent copula. The entire QAC forms a syntactic unit as an IP.

Our assumption that QACs contain a silent copula is consistent with the fact that the copula is obligatorily silent in ASL, in both standard equational ((53)) and predicational ((54)) copular sentences, and in both matrix ((53) and (54)) and embedded ((55) and (56)) clauses.

(53) THAT/SHE MARY.

'That/she is Mary.'

(54) CAR RED.

'The car is red.'

(55) JOHN THINK THAT/SHE MARY.

'John thinks that/she is Mary.'

(56) JOHN THINK CAR RED.

'John thinks the car is red.'

However, since it is very common in ASL to left-dislocate constituents conveying old information and to mark them with brow raising non-manual marking, it may be thought that an alternative syntactic analysis for QACs could be one in which the Q-constituent is left dislocated as a "syntactic topic" and the A-constituent acts as the main clause, as shown in (57). ${ }^{6}$

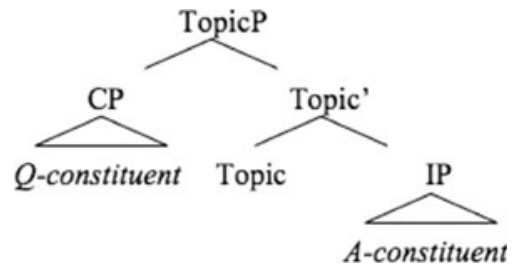

\footnotetext{
${ }^{6}$ Thanks to Matt Pearson for bringing this option to our attention.
} 
Although the brow raising non-manual marking seen on the Q-constituent can often occur with left-dislocated material that conveys old information, that is not the only place in which we see brow raising non-manual marking (e.g., we saw it also in matrix polar interrogatives in Sect. 2.4 above). Therefore, its occurrence with the Q-constituent does not necessarily indicate that the Q-constituent is in some higher/ left dislocated position.

This alternative analysis cannot easily deal with the fact that no parenthetical material can intervene between the Q-constituent and the A-constituent of a QAC, as shown in (58), where HOLD refers to a parenthetical interjection sign that we can translate as hold on. The same restriction is observed in standard predicational and identificational copular constructions in ASL, such as (59), while it does not hold between a topicalized constituent and its matrix clause, as shown in (60)-(61).

$b r$

*JOHN BUY WHAT, [HOLD], BOOK.

('What John bought was I think a book.')

*HE, [HOLD], HAPPY/ JOHN.

('He, hold on, is happy/is John.')

THAT GIRL, [HOLD], SHE HAPPY/ HAPPY SHE.

'As for that girl, hold on, she is happy.'

THAT BOY, [HOLD], HE JOHN/ JOHN HE.

'As for that boy, hold on, he is John.'

Also, while the Q-constituent always occurs in its entirety, the A-constituent is often shortened such that the only pronounced part is the one carrying new information, as discussed in Sect. 3.2. If the Q-constituent were a syntactic topic and the A-constituent the matrix clause, this would mean that a matrix clause could be almost completely elided if its left-dislocated constituent conveyed what the elided material would. We are not aware of any independent evidence for this kind of ellipsis licensing between a topic and main clause.

The very same arguments can be raised against an analysis of QACs as correlative clauses, according to which the Q-constituent would be left-dislocated, while the A-constituent would be the main clause. ${ }^{7}$

To sum up, we have argued that QACs are declarative copular sentences with the Q-constituent as an embedded interrogative in precopular position and the A-constituent as an embedded declarative in postcopular position. With these syntactic assumptions in place, let us now move on to the semantic analysis for QACs.

\footnotetext{
7 Thanks to Veneeta Dayal for suggesting this point. See Lipták (2009) for a survey of correlatives crosslinguistically.
} 


\subsection{Preliminary semantic analysis}

The basic intuition behind the semantic analysis of QACs that we argue for is that a QAC always asserts the identity of two propositions: the proposition associated with the Q-constituent and the proposition associated with the A-constituent. In what follows, we develop this intuition into a detailed compositional semantic analysis.

We start by looking at the example in (62). The syntactic and semantic facts we have discussed previously (Sects. 3 and 4.1) all point to the conclusion that the Q-constituent of a QAC is syntactically and semantically an interrogative clause. Therefore, we propose that the semantic contribution of the Q-constituent in (62) is the same as that of the corresponding matrix interrogative clause in (63) (and its English translation).

[Q-const MEG BUY WHAT], [A-const BOOK CD].

'The things Meg bought are the book and the CD., ${ }^{, 9}$

\section{MEG BUY WHAT? \\ 'What did Meg buy?'}

The tradition starting from Karttunen (1977) has suggested that the basic denotation of an interrogative clause like What did Meg buy? in a given world w is the set of propositions that constitute the true answers to What did Meg buy? in w. For instance, if the contextually salient book b and CD c are the only things that Meg bought in w, the basic denotation of (63) and the Q-constituent in (62) in w is the set in (64), which we refer to as the set $\mathrm{Q}(\mathrm{w})$ for brevity.

(64) Meaning of [Q-const MEG BUY WHAT] in a world w

$=$ the set $\mathrm{Q}(\mathrm{w})$ of propositions that are true answers to 'What did Meg buy?' in $\mathrm{w}$

$=\{\text { that Meg bought } \mathrm{b} \text {, that Meg bought } \mathrm{c} \text {, that Meg bought } \mathrm{b} \text { and } \mathrm{c}\}^{10}$

The meaning in (64), though, is not fully adequate to account for the way we use interrogative clauses, especially in embedded contexts like (65).

TIM KNOW [Embedded-interrogative MEG BUY WHAT].

'Tim knows what Meg bought.'

A verb like $K N O W$ selects for just one proposition rather than a set. For instance, it can take unambiguously proposition-denoting complements like declarative clauses, as shown in (66).

\footnotetext{
${ }^{8} B O O K$ and $C D$ can be interpreted as either definite or indefinite NPs, according to the context. Henceforth, we assume that they are interpreted referentially as definite NPs whenever they occur in our examples. For simplicity, we also assume the definite NPs $B O O K$ and $C D$ to behave like proper names in being rigid designators and having constant denotations across worlds.

9 Verbs are not marked for tense in ASL. The context or independent temporal expressions provide the temporal information. Henceforth, we assume a past interpretation of $B U Y$ in our examples.

${ }^{10}$ In this and the other definitions that follow, the sign "=", is informally used as a short cut for "is the same (object) as",.
} 


\section{(66)}

TIM KNOW [QAC MEG BUY BOOK CD].

'Tim know that Meg bought the book and the CD.'

We therefore assume that a silent answerhood operator $A n s^{11}$ applies to the interrogative clause complement of a predicate like $K N O W$ and returns the unique complete true answer within the set $\mathrm{Q}(\mathrm{w})$ that the interrogative clause denotes, that is, the unique proposition in $\mathrm{Q}(\mathrm{w})$ that entails all of the propositions in $\mathrm{Q}(\mathrm{w})$, as shown in (67).

(67) Meaning of [Q-const Ans [MEG BUY WHAT] $]$ in a world w $=$ the unique complete true answer to 'what did Meg buy?' in $\mathrm{W}$

$=$ the proposition in $\mathrm{Q}(\mathrm{w})$ that entails all of the propositions in $\mathrm{Q}(\mathrm{w})$

$=$ the proposition 'that Meg bought $\mathrm{b}$ and $\mathrm{c}$ '

Moving to the A-constituent, we have already discussed the reasons why we assume that it is always a declarative clause, though often only a sub-constituent needs to be overtly expressed. Recall that our consultants accepted either the full IP or the partially elided one (Sect. 3.2). Therefore, the A-constituent of the QAC in (62) is syntactically and semantically the same as the declarative clause in (68). As such, the A-constituent receives the standard semantic analysis in (69) as a propositiondenoting expression.

\section{[Matrix-declarative MEG BUY BOOK CD]}

'Meg bought the book and the CD.'

(69) Meaning of [A-const (MEG BUY) BOOK CD]

$=$ the proposition 'that Meg bought $\mathrm{b}$ and $\mathrm{c}$ '

As for the meaning of the whole QAC in (62), we propose that the silent copula $e_{B E}$, which-we argued-syntactically connects the Q-constituent with the A-constituent, also equates their semantic contributions. In other words, the whole QAC states that the meaning of the Q-constituent in (67) is identical to the meaning of the A-constituent in (69), as shown in (70).

(70) Meaning of [[Q-const Ans [MEG BUY WHAT]] $\mathrm{e}_{B E}\left[{ }_{A \text {-const }}\right.$ (MEG BUY) BOOK CD]] in world w

$=1$ iff the unique complete true answer to 'what did Meg buy?' in w is identical to the proposition 'that Meg bought $\mathrm{b}$ and $\mathrm{c}$ '

A detailed semantic analysis for the QAC in (62), based on the syntactic structure in (71), is given in (72). Comments follow below.

\footnotetext{
${ }^{11}$ See Heim (1994), Dayal (1996), Beck and Rullmann (1999), Lahiri (2002), and Romero (2007), a.o., for independent evidence and further discussion of this operator in spoken languages. 
(71)

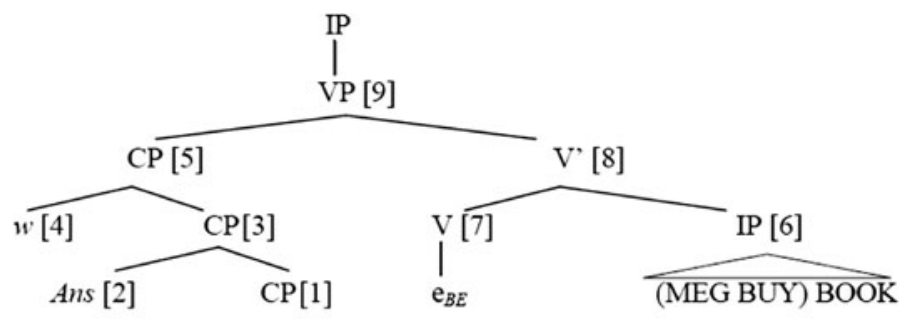

MEG BUY WHAT

(72) $[1] \quad[C P$ MEG BUY WHAT $] \rightarrow$

$\lambda \mathrm{w}_{1} \lambda \mathrm{p}_{<\mathrm{st}>}\left[\mathrm{p}\left(\mathrm{w}_{1}\right)=1 \wedge \exists \mathrm{x} .\left[\mathrm{p}=\lambda \mathrm{w}_{2} \mathbf{b u y}_{<\mathrm{e},<\mathrm{e}, \mathrm{st}>>}\left(\mathrm{w}_{2}\right)(\mathrm{x})\left(\mathrm{m}_{<e>}\right)\right]\right] \Rightarrow_{\text {def }}$

$\mathrm{Q}_{0<\mathrm{s},<\mathrm{st}, \mathrm{t}>>} 12$

[2] Ans $\rightarrow \lambda \mathrm{Q}_{<\mathrm{s},<\mathrm{st}, \mathrm{t}>>} \lambda \mathrm{w}_{3} \operatorname{ANS}\left(\mathrm{w}_{3}\right)(\mathrm{Q}) \Rightarrow_{\mathrm{def}}$

$\lambda \mathrm{Q} \lambda \mathrm{w}_{3} \lambda \mathrm{w}_{4} \cdot \forall \mathrm{p} \in \mathrm{Q}\left(\mathrm{w}_{3}\right) \cdot\left[\mathrm{p}\left(\mathrm{w}_{4}\right)=1\right]^{13}$

[3] [ ${ }_{C P}$ Ans MEG BUY WHAT] $\rightarrow \lambda \mathrm{Q} \lambda \mathrm{w}_{3}\left[\mathrm{ANS}\left(\mathrm{w}_{3}\right)(\mathrm{Q})\right]\left(\mathrm{Q}_{0}\right) \Rightarrow$ $\lambda \mathrm{w}_{3}\left[\mathrm{ANS}\left(\mathrm{w}_{3}\right)\left(\mathrm{Q}_{0}\right)\right]$

[4] $\quad w \sim \mathrm{W}_{0}$

[5] [CP $w$ Ans MEG BUY WHAT] $\rightarrow \lambda \mathrm{w}_{3}\left[\mathrm{ANS}\left(\mathrm{w}_{3}\right)\left(\mathrm{Q}_{0}\right)\right]\left(\mathrm{w}_{0}\right) \Rightarrow$ $\operatorname{ANS}\left(\mathrm{w}_{0}\right)\left(\mathrm{Q}_{0}\right) \Rightarrow$

$\lambda \mathrm{w}_{4} \cdot \forall \mathrm{p} \in \mathrm{Q}_{0}\left(\mathrm{w}_{0}\right) \cdot\left[\mathrm{p}\left(\mathrm{w}_{4}\right)=1\right]$, by [2]

[6] ${ }_{I P}\left(\mathrm{MEG}\right.$ BUY) BOOK CD] $\rightarrow \lambda \mathrm{w}_{5} \mathbf{b u y}\left(\mathrm{w}_{5}\right)\left(\mathrm{b} \oplus \mathrm{c}_{<\mathrm{e}>}\right)(\mathrm{m})$

[7] $\left[{ }_{V} \mathrm{e}_{B E}\right] \sim \lambda \mathrm{p} \lambda \mathrm{q}_{<\mathrm{st}>}[\mathrm{q}=\mathrm{p}]$

[8] $\left[V^{\prime} \mathrm{e}_{B E}[(\mathrm{MEG} \mathrm{BUY}) \mathrm{BOOK} \mathrm{CD}]\right] \sim$

$\lambda \mathrm{p} \lambda \mathrm{q}[\mathrm{q}=\mathrm{p}]\left(\lambda \mathrm{w}_{5} \mathbf{b u y}\left(\mathrm{w}_{5}\right)(\mathrm{b} \oplus \mathrm{c})(\mathrm{m})\right) \Rightarrow$

$\lambda \mathrm{q}\left[\mathrm{q}=\lambda \mathrm{w}_{5} \mathbf{b u y}\left(\mathrm{w}_{5}\right)(\mathrm{b} \oplus \mathrm{c})(\mathrm{m})\right]$

[9] $\left[v_{P}\left[\mathrm{w}\right.\right.$ Ans MEG BUY WHAT] $\left[\mathrm{e}_{B E}[(\mathrm{MEG}\right.$ BUY) BOOK CD]]] $\rightarrow$ $\lambda \mathrm{q}\left[\mathrm{q}=\lambda \mathrm{w}_{5} \mathbf{b u y}\left(\mathrm{w}_{5}\right)(\mathrm{b} \oplus \mathrm{c})(\mathrm{m})\right]\left[\operatorname{ANS}\left(\mathrm{w}_{0}\right)\left(\mathrm{Q}_{0}\right)\right] \Rightarrow$

$\operatorname{ANS}\left(\mathrm{w}_{0}\right)\left(\mathrm{Q}_{0}\right)=\lambda \mathrm{w}_{5} \mathbf{b u y}\left(w_{5}\right)(\mathrm{b} \oplus \mathrm{c})(\mathrm{m}) \Rightarrow$

$\lambda \mathrm{w}_{4} \cdot \forall \mathrm{p} \in \mathrm{Q}_{0}\left(\mathrm{w}_{0}\right) \cdot\left[\mathrm{p}\left(\mathrm{w}_{4}\right)=1\right]=\lambda \mathrm{w}_{5} \mathbf{b u y}\left(\mathrm{w}_{5}\right)(\mathrm{b} \oplus \mathrm{c})(\mathrm{m})$ by [5]

\footnotetext{
12 We adopt the convention of translating predicates of the object language like buy into the formal language by using the same string of symbols but in bold, e.g. buy. Semantic types are added only to the first occurrence of an expression in the derivation, except for the following: all expressions $x$ are of type $<\mathrm{e}>$ and all expressions $w$ are of type $<\mathrm{s}>\mathrm{w}_{0}$ is the variable over worlds whose value is independently fixed as the world of evaluation. $\mathrm{Q}_{0}$ refers to the question-intension of a given interrogative clause, while $\mathrm{Q}$ is a variable over question-intensions. In the semantic derivations, we are using the curly arrow sign " $\rightarrow$ " to indicate translation into the formal language, the thick arrow sign " $\Rightarrow$ " to indicate equivalence between formulas (with " $\Rightarrow_{\text {def }}$ " meaning equivalence by definition), and the equal sign " $=$ " for the identity relation only, in order to avoid any confusion and facilitate the reading. We are treating tense as part of the lexical entry of the verb just for simplicity.

${ }^{13}$ We use Ans to refer to the silent lexical item in ASL that carries the meaning of the answerhood operator, which we refer to in our formal language as ANS.
} 
The Q-constituent of the QAC is an interrogative CP ([1] in (72)) denoting the function $\mathrm{Q}_{0}$ of type $(<\mathrm{s},<\mathrm{st}, \mathrm{t}>>)$ that maps each world $\mathrm{w}_{1}$ to the set of propositions that constitute true answers to the question 'what did Meg buy?' in $w_{1} \cdot{ }^{14}$ The answerhood operator Ans ([2]) is defined as a function that applies to a world $\mathrm{w}_{3}$ and a function $\mathrm{Q}$ (of the same type as $\mathrm{Q}_{0}$ ) and returns the set of worlds $\mathrm{w}_{4}$ (i.e. a proposition) in which all the propositions that are in $\mathrm{Q}$ at $\mathrm{w}_{4}$ are true. In other words, Ans returns the unique answer/proposition in $\mathrm{Q}$ at $\mathrm{w}_{4}$ that entails all the answers/propositions in $\mathrm{Q}$ at $\mathrm{w}_{4}$. Therefore, when Ans applies to its CP sister within the Q-constituent ([3]) and then to the node that is translated into the world variable $\mathrm{w}_{0}([4])$, it returns the unique proposition in $\mathrm{Q}$ at $\mathrm{w}_{4}$ that entails all the propositions inside $\mathrm{Q}_{0}$ at $\mathrm{w}_{0}$ (with $\mathrm{w}_{0}$ referring to the world of evaluation) ([5]).

The A-constituent of the QAC is an IP that denotes the proposition 'that Meg bought $\mathrm{b} \oplus \mathrm{c}^{\prime}([6])$. We are assuming plural individuals among our entities and we use the symbol $b \oplus c$ to refer to the plural individual resulting from the sum of the atomic individuals b and c (Link 1983). Consequently, every individual variable is supposed to be ranging over atomic and plural individuals.

The silent copula $e_{B E}$ glues the Q-constituent and the A-constituent together by denoting an identity relation ([7]). It combines with the IP in [6] denoting the proposition 'that Meg bought $\mathrm{b} \oplus \mathrm{c}$ ', and returns the $\mathrm{V}$ ' denoting the set of propositions that are equivalent to 'that Meg bought $\mathrm{b} \oplus \mathrm{c}$ ' ([8]). The VP ([9]) resulting from combining the $\mathrm{V}$ ' and $\mathrm{CP}$ denotes the truth value 1 iff the proposition denoted by the $\mathrm{CP}$ in [5] is a member of the set in [8]. In other words, the silent copula returns 1 iff the proposition denoted by the Q-constituent and the proposition denoted by the A-constituent are equivalent.

If the world of evaluation $w_{0}$ in [9] is such that Meg bought a book b, a CD c, and nothing else, then $\mathrm{Q}_{0}$ would be identical to the set of propositions in (73).

$$
\mathrm{Q}_{0}\left(\mathrm{w}_{0}\right)=\left\{\lambda \mathrm{w}_{5} \operatorname{buy}\left(\mathrm{w}_{5}\right)(\mathrm{b})(\mathrm{m}), \lambda \mathrm{w}_{5} \mathbf{b u y}\left(\mathrm{w}_{5}\right)(\mathrm{c})(\mathrm{m}), \lambda \mathrm{w}_{5} \mathbf{b u y}\left(\mathrm{w}_{5}\right)(\mathrm{b} \oplus \mathrm{c})(\mathrm{m})\right\}
$$

Since $\lambda \mathrm{w}_{5} \operatorname{buy}\left(\mathrm{w}_{5}\right)(\mathrm{b} \oplus \mathrm{c})(\mathrm{m})$ in $\mathrm{Q}_{0}\left(\mathrm{w}_{0}\right)$ entails the other two propositions, the identity in (74) holds, which is exactly what [9] in (72) states.

$$
\lambda \mathrm{w}_{4} \cdot \forall \mathrm{p} \in \mathrm{Q}_{0}\left(\mathrm{w}_{0}\right) \cdot\left[\mathrm{p}\left(\mathrm{w}_{4}\right)=1\right]=\lambda \mathrm{w}_{5} \mathbf{b u y}\left(\mathrm{w}_{5}\right)(\mathrm{b} \oplus \mathrm{c})(\mathrm{m})
$$

However, the semantic analysis of QACs we just presented is not fully adequate and needs to be developed further in order to account for the full range of semantic properties that QACs exhibit, in particular the facts discussed in the next section.

\footnotetext{
${ }^{14}$ We are assuming that an interrogative clause denotes the set of its true answers in a given world (Karttunen 1977). Nothing crucial hinges on this assumption. Our proposal could be easily reformulated if, instead, an interrogative clause were assumed to denote the set of all possible answers in a given world, no matter whether they are true or false (Hamblin 1973).
} 
4.3 Exhaustivity in QACs

\subsubsection{Exhaustivity in matrix QACs}

As already noticed in Petronio (1991), QACs exhibit "exhaustivity." In the scenario in (75), the QAC in (75a) is infelicitous because the A-constituent only mentions one of the objects that Meg bought. The listing of the objects Meg bought is not complete, not "exhaustive." On the other hand, the QAC in (75b), in which both objects are mentioned, is fully felicitous. Interestingly, the QAC in (75a) patterns like the QAC in (75c) in being infelicitous. The latter contains the sign FINISH ('nothing else'/ that's it'), which overtly marks the fact that the list (in this case, just a one-item list) should be interpreted as exhaustive. On the other hand, the QAC in (75b) is as felicitous as the QAC in (75d), containing the exhaustivity marker FINISH.

(75) Scenario: Meg bought the contextually salient book and CD.

a. \# MEG BUY WHAT, BOOK.

'The thing/What Meg bought is the book.'

b. MEG BUY WHAT, BOOK, CD.

'The things/What Meg bought are/is the book and the CD.'

c. \# MEG BUY WHAT, BOOK FINISH.

'The thing/What Meg bought is the book and nothing else.'

d. MEG BUY WHAT, BOOK, CD FINISH.

'The things/What Meg bought are/is the book, the CD, and nothing else.'

The pattern in (75) shows that QACs require the A-constituent to answer the question conveyed by the Q-constituent exhaustively, even if an overt marker of exhaustivity like FINISH is not present.

The same exhaustivity requirements apply to discourse-level question-answer pairs in ASL (and in English) as well. In the same scenario as (75), the matrix question in (76a) cannot be answered felicitously if only one object is mentioned $((76 b))$ - both objects need to be mentioned $((76 \mathrm{c}))$. This is the same pattern that is triggered by the presence of an overt exhaustivity marker like FINISH (cf. (76d) vs. (76e)). Once again, QACs and discourse-level question-answer pairs pattern alike.

(76) Scenario: Meg bought the contextually salient book and CD.

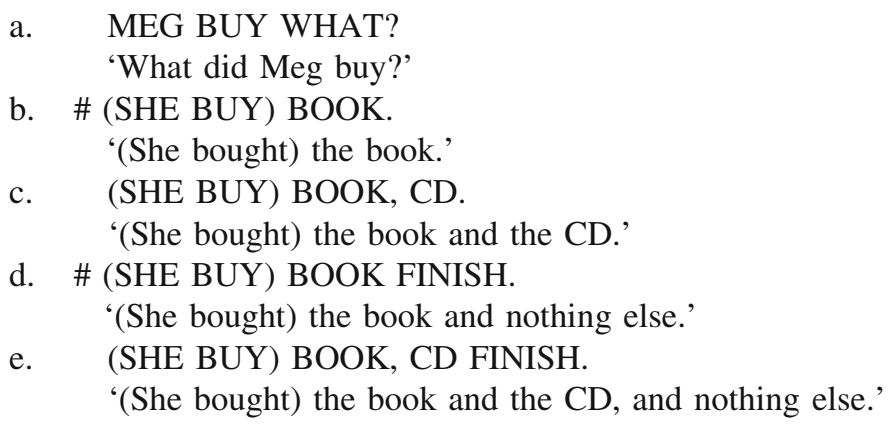


Notice that when a sentence like MEG/SHE BUY BOOK in (76b) is not used as an answer to a question like (76a), then it is not necessarily interpreted exhaustively. In other words, (76b) is not necessarily equivalent to a sentence with an overt marker of exhaustification like (76d). For instance, in a scenario like (77) or (78), MEG/SHE BUY BOOK can be uttered felicitously even if Meg bought more things than just a book.

(77) Scenario: Meg bought the contextually salient book and CD. She always buys CDs, but she never buys books. The speaker is really surprised and utters:

MEG BUY BOOK!

'Meg bought the book!'

(78) Scenario: Meg bought the contextually salient book and CD, while Tim bought the DVD and the cake.
a. BUY BOOK WHO?
'Who bought the book?'
b. MEG (BUY BOOK).
'Meg (bought the book).'

It has been noticed that an answer to a question can receive a partial or nonexhaustive interpretation-the so-called "mention-some", interpretation-under certain conditions. ${ }^{15}$ For instance, in the scenario in (79), a question like (79a) allows for an answer like (79b), in which only one of the three places in which coffee can be found is mentioned. The same holds in ASL, as shown in (79c,d).

(79) Scenario: Starbucks is one of three places where one can find coffee in the area considered to be relevant.
a. Speaker A: Where can I find coffee?
b. Speaker B: At Starbucks.
c. Signer $A$ : CAN FIND COFFEE WHERE?
'Where can I find coffee?'
d. Signer B: STARBUCKS.
'Starbucks.'

What has not been noticed before is that, once again, QACs exhibit the same pattern as discourse-level question-answer pairs. For instance, in (80), the A-constituent is interpreted as conveying a partial/non-exhaustive answer to the question expressed by the Q-constituent, since only one of the contextually relevant coffee places is mentioned.

\footnotetext{
15 It is an open issue what constitutes the complete list of the conditions that allow/require mention-some readings, and how they produce the reading that they do. See Beck and Rullmann (1999, Sect. 9), Groenendijk and Stokhof (1994), and Heim (1994), a.o., for further discussion of mention-some readings.
} 
(80) Scenario: Starbucks is one of three places where one can find coffee in the area considered to be relevant.

CAN FIND COFFEE WHERE, STARBUCKS.

'You can find coffee at Starbucks.'

\subsubsection{Exhaustivity in embedded QACs}

Groenendijk and Stokhof $(1982,1984)$ argue that there are predicates like know that unambiguously impose a stronger form of exhaustivity on the interpretation of their interrogative complement. According to this view, a sentence like (82) is false in a scenario like (81). We share this intuition. ${ }^{16}$

(81) Scenario: Meg bought the contextually salient book (b) and CD (c), and nothing else. Tim knows that Meg bought the book and the CD, but he is unsure if she bought the contextually salient DVD (d) as well.

(82) Tim knows [what Meg bought].

The reason-they argue-is that a predicate like know requires its interrogative complement to be interpreted as denoting the proposition 'that Meg bought $\mathrm{b} \oplus \mathrm{c}$ and nothing else' - the so-called 'strongly exhaustive' interpretation of the interrogative clause. This is different from the semantics for interrogatives we have assumed so far, which would assign the 'weakly exhaustive' interpretation to the constituent interrogative in (82). In the scenario in (81) above, the weakly exhaustive interpretation corresponds to the proposition 'that Meg bought $\mathrm{b} \oplus \mathrm{c}$ ' - a proposition that Tim knows to be true. Therefore, the whole sentence in (82) is incorrectly predicted to be true. On the other hand, the strongly exhaustive interpretation of the interrogative complement is the proposition 'that Meg bought $\mathrm{b} \oplus \mathrm{c}$ and nothing else', which - though true-is not part of Tim's knowledge, since Tim is unsure if Meg bought the DVD as well. Therefore, under a strongly exhaustive interpretation of the interrogative clause, (82) is correctly predicted to be false.

In the very same scenario as (81), the ASL equivalent of (82) in (83) is judged false as well.

\section{TIM KNOW [WHAT MEG BUY]}

'Tim knows what Meg bought.'

QACs exhibit a similar pattern. In the same scenario as (81), the QAC in (84) is judged false, since Tim does not know that Meg bought just the book and the CD. We have similar intuitions for the English translation of (84), which has a specificational clause in the complement position of the propositional attitude predicate.

\footnotetext{
16 See Guerzoni and Sharvit (2007) and Romero (2007) for a different view, according to which know can allow for a weaker exhaustive reading.
} 
(84)

TIM KNOW [QAC [Q-const MEG BUY WHAT], [A-const (MEG BUY)

BOOK CD]].

'Tim knows that the things that Meg bought are the book and the CD.'

\subsubsection{A problem with exhaustivity in QACs and our current analysis}

Our current analysis faces a problem related to exhaustivity, though: it does not account for the semantic behavior of matrix QACs like the one we saw in (75d) above, repeated in (85) below.

(85) $[Q A C[Q$-const MEG BUY WHAT], [A-const BOOK, CD FINISH]].

'The things/What Meg bought are/is the book and the CD (and nothing else).'

Our analysis equates the meaning of the Q-constituent with the meaning of the A-constituent. The meaning that is assigned to the Q-constituent is given in (86).

$$
\left[Q \text {-const Ans MEG BUY WHAT] } \rightarrow \lambda \mathrm{w}_{1} \cdot \forall \mathrm{p} \in \mathrm{Q}_{0}\left(\mathrm{w}_{0}\right) \cdot\left[\mathrm{p}\left(\mathrm{w}_{1}\right)=1\right]\right.
$$

The meaning that is assigned to the A-constituent is given in (87). The semantic contribution of FINISH is translated into the right conjunct in (87), which requires that the only things that are salient in the context $\mathrm{C}$ and have been bought by Meg are the book and/or the CD.

$$
\begin{aligned}
& {[A \text {-const } \mathrm{BOOK}, \mathrm{CD} \text { FINISH] } \sim} \\
& \lambda \mathrm{w}_{1}\left[\mathbf{b u y}\left(\mathrm{w}_{1}\right)(\mathrm{b} \oplus \mathrm{c})(\mathrm{m}) \wedge \forall \mathrm{x} \in \mathrm{C} .\left[\mathbf{b u y}\left(\mathrm{w}_{1}\right)(\mathrm{x})(\mathrm{m}) \rightarrow \mathrm{x} \leq \mathrm{b} \oplus \mathrm{c}\right]^{17}\right.
\end{aligned}
$$

In a scenario in which Meg bought the book and the CD and nothing else, (86) would end up being the proposition 'that Meg bought $\mathrm{b} \oplus \mathrm{c}$ ' in (88), as already discussed in (73)-(74) above.

$$
\lambda \mathrm{w}_{1} \mathbf{b u y}\left(\mathrm{w}_{1}\right)(\mathrm{b} \oplus \mathrm{c})(\mathrm{m})
$$

The silent copula $e_{B E}$ that connects the two main constituents equates them, but the propositions in (87) and (88) are not the same-(87) entails (88), but (88) does not entail (87) - and cannot be the same. In fact, the answerhood operator Ans in (86) never returns a proposition like (87), since Ans applies to the set $\mathrm{Q}_{0}\left(\mathrm{w}_{0}\right)$ of true answers to the question in $\mathrm{w}_{0}$ and returns the answer that entails the others, which is always a member of $\mathrm{Q}_{0}\left(\mathrm{w}_{0}\right)$. But, due to the way $\mathrm{Q}_{0}\left(\mathrm{w}_{0}\right)$ is defined (cf. (72)[1]), $\mathrm{Q}_{0}\left(\mathrm{w}_{0}\right)$ never contains 'exhaustified' propositions, i.e., it never contains a proposition that is true under the further restrictions that are conveyed by the right conjunct in (87).

In conclusion, QACs exhibit the same exhaustivity pattern as discourse-level question-answer pairs and the same strong exhaustivity as embedded interrogatives. These facts bring further support to an analysis like ours that treats QACs as closely related to discourse-level question-answer pairs and as having an interrogative

\footnotetext{
17 " $\leq$ " stands for the part-of relationship between plural individuals and their (atomic) parts.
} 
clause as their Q-constituent. But it also asks for a revision of our current analysis in order to handle the problem we just discussed. We present such a revision in the next section.

\subsection{Final semantic analysis}

In order to handle the problem in Sect. 4.3, we maintain the core idea of our analysis that a QAC is made of two clauses conveying two propositions that are equated, but we suggest a slight change in the interpretation of the two main constituents, resulting in them denoting the same "exhaustified" proposition. We propose that the A-constituent of a QAC is always interpreted as if there were an exhaustivity marker like FINISH present, even when it is not overtly signed. The interpretation of the Q-constituent must be revised as well, in order to return an "exhaustified", proposition as the complete true answer to the question. In what follows, we argue that this result can be achieved by making use of two silent operators that have been independently argued for in the grammar: an answerhood operator applying to the Q-constituent (different from the one already introduced in Sect. 4.2) and an exhaustivity operator applying to the A-constituent. We present and discuss them in turn, starting with the Q-constituent.

\subsubsection{Revised semantic analysis for the Q-constituent}

Heim (1994) and subsequent related work (Beck and Rullmann 1999; Romero 2007, a.o.) argue that the strongly exhaustive interpretation of interrogatives does not need to be built into their semantics (contra Groenendijk and Stokhof 1982, 1984: Ch. 2), but instead can result from an answerhood operator related to but different from the one we introduced earlier (Sect. 4.2). We argue that Heim's new answerhood operator applies to the Q-constituent of QACs as well. We rename the answerhood operator that was introduced in (72: [2]) $A n s_{W E A K}$ and repeat it (with minor changes) in (89a) below for easy comparison. We call the new operator $A$ s $_{S T R O N G}$, instead, and define it in (89b), following Heim (1994).

$$
\begin{array}{ll}
\text { a. } & A n s_{W E A K} \leadsto \lambda \mathrm{Q} \lambda \mathrm{w}_{1} \operatorname{ANS}_{\mathrm{WEAK}}\left(\mathrm{w}_{1}\right)(\mathrm{Q}) \Rightarrow_{\text {def }} \\
& \lambda \mathrm{Q} \lambda \mathrm{w}_{1} \lambda \mathrm{w}_{2} \cdot \forall \mathrm{p} \in \mathrm{Q}\left(\mathrm{w}_{1}\right) \cdot\left[\mathrm{p}\left(\mathrm{w}_{2}\right)=1\right]
\end{array}
$$

(cf. (72:[1]) for the definition of Q)

b. $\quad A n s_{\text {STRONG }} \rightarrow \lambda \mathrm{Q} \lambda \mathrm{w}_{1} \operatorname{ANS}_{\mathrm{STRONG}}\left(\mathrm{w}_{1}\right)(\mathrm{Q}) \Rightarrow$

$$
\lambda \mathrm{Q} \lambda \mathrm{w}_{1} \lambda \mathrm{w}_{2}\left[\operatorname{ANS}_{\mathrm{WEAK}}\left(\mathrm{w}_{1}\right)(\mathrm{Q})=\operatorname{ANS}_{\mathrm{WEAK}}\left(\mathrm{w}_{2}\right)(\mathrm{Q})\right]
$$

The definition of $A n s_{S T R O N G}$ in (89b) relies on $A n s_{W E A K}$. It states that $A n s_{S T R O N G}$ applies to a question-intension $\mathrm{Q}$ and a world $\mathrm{w}_{1}$ to return a proposition, i.e., a set of worlds. These are all the worlds $w_{3}$ in which the value of $A n s_{W E A K}$ for the question

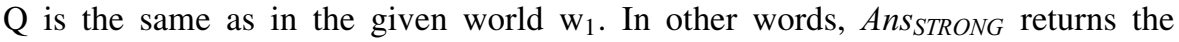
proposition that is true in all the worlds $w_{3}$ in which the complete true answer to the question $\mathrm{Q}$ is the same as in the given world $\mathrm{w}_{1}$.

If $A n s_{\text {STRONG }}$ is applied to the Q-constituent of the QAC in (90), the QAC receives a strongly exhaustive interpretation, as desired. 
(90)

[Q-const Ans STRONG $_{\text {[CP }}$ MEG BUY WHAT]], [A-const Exh [IP (MEG BUY)

BOOK, CD]]

'The things Meg bought are the book and the CD.'

$$
\begin{aligned}
& {\left[Q \text {-const } \text { Ans }_{\text {STRONG }}[\text { CP MEG BUY WHAT] }] \rightarrow\right.} \\
& \lambda \mathrm{Q} \lambda \mathrm{w}_{1}\left[\mathrm{ANS}_{\mathrm{STRONG}_{\text {TRO }}}\left(\mathrm{w}_{1}\right)(\mathrm{Q})\right]\left(\mathrm{Q}_{0}\right)\left(\mathrm{w}_{0}\right) \Rightarrow \\
& \operatorname{ANS}_{\mathrm{STRONG}}\left(\mathrm{w}_{0}\right)\left(\mathrm{Q}_{0}\right) \Rightarrow \\
& \lambda \mathrm{w}_{1}\left[\mathrm{ANS}_{\mathrm{WEAK}}\left(\mathrm{w}_{0}\right)\left(\mathrm{Q}_{0}\right)=\operatorname{ANS}_{\mathrm{WEAK}}\left(\mathrm{w}_{1}\right)\left(\mathrm{Q}_{0}\right)\right]
\end{aligned}
$$

(91) states that the Q-constituent of (90) denotes the proposition that is true in all those worlds in which the complete true answer to 'what did Meg buy?' is the same as in the world of evaluation $w_{0}$. If we assume the usual world $w_{0}$ in which Meg bought the contextually salient book and $\mathrm{CD}$, then (91) ends up meaning the proposition 'that Meg bought $\mathrm{b} \oplus \mathrm{c}$ and nothing else'-the proposition that is true in all worlds in which the true answer to the question 'what did Meg buy?' is the proposition 'that Meg bought $\mathrm{b} \oplus \mathrm{c}$ '.

As mentioned earlier, Ans STRONG $_{\text {has }}$ been independently argued for to handle the strongly exhaustive interpretation of the interrogative complements of predicates like know. The (implicit/explicit) assumption is that Ans STRONG $_{\text {in }}$ is licensed by predicates like know in their complement position or is directly incorporated in their lexical entry. Romero (2007) argues that $A$ s $_{\text {STRONG }}$ is needed to account for strong exhaustivity in two other constructions: (i) NPs interpreted as concealed questions in the complement position of the equivalent of know in Spanish, and (ii) NPs in the subject position of specificational copular sentences in Spanish. ${ }^{18}$ QACs may be taken as a further construction supporting the need for $A$ S $_{\text {STRONG }}$ in the grammar. In

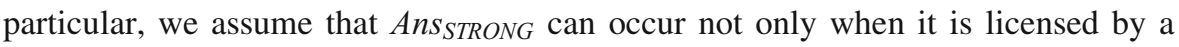
lexical item, but also in order to solve a type mismatch between the basic denotation of an interrogative clause (a question-intension) and the selectional restrictions of the predicate of which the interrogative clause is an argument. In a QAC, the basic denotation of the Q-constituent is a question-intension $(<\mathrm{s},<\mathrm{st}, \mathrm{t}\rangle>)$, which is of a different type from the proposition denoted by the A-constituent $(<\mathrm{st}>)$. Therefore, the two cannot be equated by the copula without $A n s_{S T R O N G}$ applying to the Qconstituent first.

\subsubsection{Revised semantic analysis for the A-constituent}

Section 4.3 showed that the A-constituent is interpreted exhaustively with respect to one of its sub-constituents. We propose that this is due to a silent exhaustivity operator Exh. The operator Exh is borrowed from Chierchia et al (2009, to appear),

\footnotetext{
18 Romero (2007) also argues that two more answerhood operators are needed in order to account for the full range of interpretations of the two constructions she investigates: Ans ${ }_{W E A K}$ and Ans SOME $_{\text {. In }}$ Sect. 4.4.4 below, we suggest that QACs that do not exhibit exhaustivity can be accounted for by means of $A n s_{S O M E}$, which we call $A n s_{N O N-E X H}$. Finally, the QACs whose interpretation our preliminary analysis in Sect. 4.2 can account for may be argued to necessitate just $A n s_{\text {WEAK }}$ rather than the stronger Ans STRONG $_{\text {, }}$ which is needed for the problematic QACs in Sect. 4.3. We prefer to keep the picture simple and assume

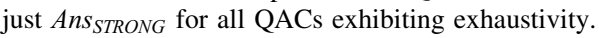


who in turn are inspired by Rooth's (1992) and Krifka's (1993) analyses of only in English. Chierchia et al. (2009, to appear) use Exh to account for scalar implicatures as a grammatical phenomenon, rather than a discourse-level phenomenon. An older formulation of this idea in Chierchia (2004) has been used to account for the semantic behavior of the post-copular constituent in specificational pseudoclefts (Schlenker 2003) and specificational clauses (Romero 2007).

We believe that QACs further support the need for this operator in the grammar, since-we argue-Exh needs to apply to the A-constituent of a QAC as well in order to fully account for the semantic behavior of QACs. Syntactically, Exh combines with the IP within the A-constituent as an adjunct to the left, as shown in (92). Semantically, it takes the proposition $\mathrm{p}$ that is denoted by the A-constituent and a set $\mathrm{A}$ of propositions that are alternatives to $\mathrm{p}$ (to be defined shortly) and returns the set of worlds (i.e. a proposition) in which $\mathrm{p}$ is true and no other proposition in $\mathrm{A}$ is true except those that are entailed by p, as shown in (93).

$$
\begin{aligned}
& {\left[{ }_{A \text {-const }} \operatorname{Exh} \mathrm{IP}\right]} \\
& \operatorname{Exh} \rightarrow \lambda \mathrm{p}_{<\mathrm{st}>} \lambda \mathrm{A}_{<\mathrm{st}, \mathrm{t}>} \operatorname{EXH}(\mathrm{p})(\mathrm{A}) \Rightarrow \\
& \lambda \mathrm{p} \lambda \mathrm{A} \lambda \mathrm{w}_{1}\left[\mathrm{p}\left(\mathrm{w}_{1}\right)=1 \wedge \forall \mathrm{q}_{<\mathrm{st}>} \in \mathrm{A}\left[\mathrm{q}\left(\mathrm{w}_{1}\right)=1 \rightarrow(\mathrm{p} \rightarrow \mathrm{q})\right]\right]^{19}
\end{aligned}
$$

Let's now define the set of alternatives A and show how Exh works in detail, by looking at the specific example of the A-constituent in the QAC in (90), repeated in (94) below.

$$
\text { [A-const } \left.\operatorname{Exh}\left[{ }_{I P}(\mathrm{MEG} \mathrm{BUY}) \mathrm{BOOK}, \mathrm{CD}\right]\right]
$$

The denotation of the IP in (94) is the proposition 'that Meg bought $b \oplus c$ '. When Exh applies, it returns the proposition 'that Meg bought $\mathrm{b} \oplus \mathrm{c}$ and nothing else'. To see how this result is achieved, we first need to define the set $\mathrm{A}_{0}$ of alternatives to the proposition denoted by the IP of the A-constituent with respect to its object, as in (95). The set $A_{0}$ contains all the (true or false) propositions that result from assigning all of the individuals in the contextually relevant set $\mathrm{C}$ to the variable $\mathrm{x}$ in the object position of the predicate buy:

$$
\begin{aligned}
& \text { The set } \mathrm{A}_{0} \text { of alternatives of }\left[{ }_{I P}(\mathrm{MEG} \text { BUY) BOOK, } \mathrm{CD}] \text { given } \mathrm{C}\right. \\
& =\left\{\mathrm{p}: \exists \mathrm{x} \in \mathrm{C} \cdot\left[\mathrm{p}=\lambda w_{1} \text { buy }\left(\mathrm{w}_{1}\right)(\mathrm{x})(\mathrm{m})\right]\right\}
\end{aligned}
$$

If we assume that the only contextually salient objects are the book (b), the CD (c), and the DVD (d), then the set $\mathrm{C}$ in (95) is identical to $\{\mathrm{b}, \mathrm{c}, \mathrm{d}\}$ and the set of alternatives in (95) is equivalent to (96).

(96) The set $\mathrm{A}_{0}$ of alternatives of [IP (MEG BUY) BOOK, CD] given $\mathrm{C}$ if $\mathrm{C}$ is $\{b, c, d\}$

$=\{$ that Meg bought $\mathrm{b}$, that Meg bought $\mathrm{c}$, that Meg bought $\mathrm{d}$, that Meg bought $\mathrm{b} \oplus \mathrm{c}$, that Meg bought $\mathrm{c} \oplus \mathrm{d}$, that Meg bought $\mathrm{b} \oplus \mathrm{d}$, that Meg bought $\mathrm{b} \oplus \mathrm{c} \oplus \mathrm{d}\}$

\footnotetext{
19 Similarly to the answerhood operator, we refer to the lexical item in ASL as Exh and to its equivalent in the formal language as EXH.
} 
The alternatives of the A-constituent in (95) and (96) are calculated with respect to the object rather than any other sub-constituent inside the A-constituent (e.g. the subject) because the object is marked in two ways. First, it is the only sub-constituent within the A-constituent that must be signed and cannot remain covert. Second, if the whole clausal A-constituent is signed, then the object must be signed with more emphasis. In general, we take the marked status of the obligatorily overt constituent in the A-constituent as the trigger for both the calculation of a set of alternatives and for the choice of the specific alternatives/propositions that are in the set.

Returning to the A-constituent in (94), the exhaustivity operator Exh is licensed because the A-constituent contains a marked/focused sub-constituent. Exh triggers the calculation of alternatives with respect to the object argument since the object [BOOK, CD] is the marked constituent. Exh applies to the basic denotation of the A-constituent (i.e. the proposition 'that Meg bought $b \oplus c$ ') and the set of its alternatives $\mathrm{A}_{0}$ (i.e. the set of propositions in (95) and (96)) and returns the proposition that is true whenever the proposition 'that Meg bought $\mathrm{b} \oplus \mathrm{c}$ ' is true and no proposition in the set of alternatives is true, unless it is entailed by the proposition 'that Meg bought $b \oplus c$ ', as shown in (97).

$$
\begin{aligned}
& {\left[{ }_{A \text {-const }} \operatorname{Exh}\left[_{I P}(\mathrm{MEG} \mathrm{BUY}) \mathrm{BOOK}, \mathrm{CD}\right]\right] \leadsto} \\
& \lambda \mathrm{p} \lambda \mathrm{A}[\mathrm{EXH}(\mathrm{p})(\mathrm{A})]\left(\lambda \mathrm{w}_{1} \text { buy }\left(\mathrm{w}_{1}\right)(\mathrm{b} \oplus \mathrm{c})(\mathrm{m})\right)\left(\mathrm{A}_{0}\right) \Rightarrow \\
& \operatorname{EXH}\left(\lambda \mathrm{w}_{1} \operatorname{buy}\left(\mathrm{w}_{1}\right)(\mathrm{b} \oplus \mathrm{c})(\mathrm{m})\right)\left(\mathrm{A}_{0}\right) \Rightarrow \\
& \lambda \mathrm{w}_{1}\left[\mathrm{buy}\left(\mathrm{w}_{1}\right)(\mathrm{b} \oplus \mathrm{c})(\mathrm{m})=1 \wedge\right. \\
& \forall \mathrm{q} \in \mathrm{A}_{0} \cdot\left[\mathrm{q}\left(\mathrm{w}_{1}\right)=1 \rightarrow\left[\left(\lambda \mathrm{w}_{2} \mathbf{b u y}\left(\mathrm{w}_{2}\right)(\mathrm{b} \oplus \mathrm{c})(\mathrm{m}) \rightarrow \mathrm{q}\right)\right]\right] \text { by }(93) \\
& \qquad \quad \text { for } \mathrm{A}_{0}=\left\{\mathrm{p}: \exists \mathrm{x} \in \mathrm{C} \cdot\left[\mathrm{p}=\lambda \mathrm{w}_{1} \mathbf{b u y}\left(\mathrm{w}_{1}\right)(\mathrm{x})(\mathrm{m})\right]\right\}
\end{aligned}
$$

Since we are assuming $\mathrm{C}$ to contain only $\mathrm{b}, \mathrm{c}$, and $\mathrm{d}$, there is only one proposition in the set $\mathrm{A}_{0}$ that is not entailed by 'that Meg bought $\mathrm{b} \oplus \mathrm{c}$ ', i.e., 'that Meg bought $\mathrm{d}$ '. Therefore, (97) is equivalent to (98).

$$
\begin{aligned}
& {\left[{ } _ { A \text { -const } } \operatorname { E x h } \left[{ }_{I P}(\mathrm{MEG} \text { BUY) BOOK, CD]] } \rightarrow\right.\right.} \\
& \lambda \mathrm{w}_{1}\left[\mathbf{b u y}\left(\mathrm{w}_{1}\right)(\mathbf{b} \oplus \mathbf{c})(\mathrm{m})=1 \wedge \neg \mathbf{b u y}\left(\mathrm{w}_{1}\right)(\mathrm{d})(\mathrm{m})\right]
\end{aligned}
$$

\subsubsection{Revised semantic analysis for the whole QAC}

With this revised semantics for the Q-constituent and the A-constituent in hand, we can now return to the issue of the semantics of the whole QAC. Our core idea is that a QAC asserts the identity of the semantic contributions of the Q-constituent and the A-constituent. We have just concluded that both constituents denote a proposition. The semantics for the whole QAC in (99) requires that the proposition denoted by the $\mathrm{Q}$-constituent in the given world $\mathrm{w}_{0}$ be the same as the proposition denoted by the A-constituent. 
(99) [[Q-const Ans $_{\text {STRONG }}\left[{ }_{C P}\right.$ MEG BUY WHAT $\left.]\right]$, $\left.\left[e_{B E}\left[{ }_{A-\text { const }} \operatorname{Exh}\left[_{I P}(\mathrm{MEG} \mathrm{BUY}) \mathrm{BOOK}, \mathrm{CD}\right]\right]\right]\right] \sim$

$$
\begin{aligned}
& \operatorname{ANS}_{\text {STRONG }}\left(\mathrm{w}_{0}\right)\left(\mathrm{Q}_{0}\right)=\operatorname{EXH}\left(\lambda \mathrm{w}_{1} \text { buy }\left(\mathrm{w}_{1}\right)(\mathrm{b} \oplus \mathrm{c})(\mathrm{m})\right)\left(\mathrm{A}_{0}\right) \Rightarrow \\
& \lambda \mathrm{w}_{2}\left[\operatorname{ANS}_{\text {WEAK }}\left(\mathrm{w}_{0}\right)\left(\mathrm{Q}_{0}\right)=\operatorname{ANS}_{\text {WEAK }}\left(\mathrm{w}_{2}\right)\left(\mathrm{Q}_{0}\right)\right]=
\end{aligned}
$$$$
\lambda \mathrm{w}_{1}\left[\mathbf{b u y}\left(\mathrm{w}_{1}\right)(\mathrm{b} \oplus \mathrm{c})(\mathrm{m})=1 \wedge \neg \mathbf{b u y}\left(\mathrm{w}_{1}\right)(\mathrm{d})(\mathrm{m})\right]
$$

Our new analysis of QACs in (99) does not face the problem of our preliminary analysis that was discussed in Sect. 4.3.3. In fact, it correctly accounts for QACs like (100), in which the A-constituent contains the exhaustivity marker FINISH. The analysis of the A-constituent has been reformulated in such a way that exhaustification with respect to a marked constituent always takes place, regardless of the presence of an overt exhaustivity marker.

(100) [MEG BUY WHAT], [BOOK, CD FINISH].

'The things/What Meg bought are/is the book and the CD (and nothing else).'

We conclude this section with a fully detailed analysis of the QAC in (99). The syntactic tree is given in (101), while the semantic derivation is provided in (102).

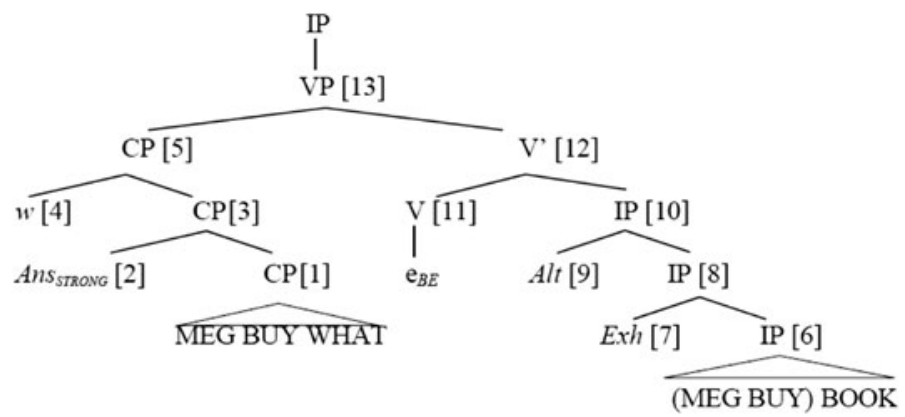

(102) $[1] \quad\left[{ }_{C P}\right.$ MEG BUY WHAT $] \sim$

$\lambda \mathrm{w}_{1} \lambda \mathrm{p}\left[\mathrm{p}\left(\mathrm{w}_{1}\right)=1 \wedge \exists \mathrm{x}\left[\mathrm{p}=\lambda \mathrm{w}_{2} \operatorname{buy}\left(\mathrm{w}_{2}\right)(\mathrm{x})(\mathrm{m})\right]\right] \Rightarrow_{\text {def }} \mathrm{Q}_{0}$

[2] Ans $_{\text {STRONG }} \sim \lambda \mathrm{Q} \lambda \mathrm{w}_{1} \mathrm{ANS}_{\mathrm{STRONG}}\left(\mathrm{w}_{1}\right)(\mathrm{Q})$

[3] $\left[{ }_{C P}\right.$ Ans $_{\text {STRONG }}\left[{ }_{C P}\right.$ MEG BUY WHAT $\left.]\right] \leadsto$ $\lambda \mathrm{Q} \lambda \mathrm{w}_{1}\left[\operatorname{ANS}_{\mathrm{STRONG}}\left(\mathrm{w}_{1}\right)(\mathrm{Q})\right]\left(\mathrm{Q}_{0}\right) \Rightarrow$ $\lambda \mathrm{w}_{1} \mathrm{ANS}_{\mathrm{STRONG}}\left(\mathrm{w}_{1}\right)\left(\mathrm{Q}_{0}\right)$

[4] $\quad w \sim \mathrm{w}_{0}$

[5] $\left[{ }_{C P} w\right.$ Ans $_{S T R O N G}$ MEG BUY WHAT $] \sim$ $\lambda \mathrm{w}_{1}\left[\mathrm{ANS}_{\mathrm{STRONG}}\left(\mathrm{w}_{1}\right)\left(\mathrm{Q}_{0}\right)\right]\left(\mathrm{w}_{0}\right) \Rightarrow$ $\operatorname{ANS}_{\text {STRONG }}\left(\mathrm{w}_{0}\right)\left(\mathrm{Q}_{0}\right)$ 
[6] ${ }_{I P}\left(\mathrm{MEG}\right.$ BUY) BOOK CD] $\rightarrow \lambda \mathrm{w}_{2} \mathbf{b u y}\left(\mathrm{w}_{2}\right)(\mathrm{b} \oplus \mathrm{c})(\mathrm{m})$

[7] $E x h \rightarrow \lambda \mathrm{p} \lambda \mathrm{A}[\operatorname{EXH}(\mathrm{p})(A)]$ by (93)

[8] [ ${ }_{I P} E x h(\mathrm{MEG}$ BUY) BOOK CD] $\rightarrow$ $\lambda \mathrm{p} \lambda \mathrm{A}[\operatorname{EXH}(\mathrm{p})(\mathrm{A})]\left(\lambda \mathrm{w}_{2} \mathbf{b u y}\left(\mathrm{w}_{2}\right)(\mathrm{b} \oplus \mathrm{c})(\mathrm{m})\right) \Rightarrow$ $\lambda$ A.EXH $\left[\lambda \mathrm{w}_{2} \mathbf{b u y}\left(\mathrm{w}_{2}\right)(\mathrm{b} \oplus \mathbf{c})(\mathrm{m})\right]$

[9] Alt $\rightarrow \mathrm{A}_{0}$ by (95)

[10] $\quad\left[{ }_{I P}\right.$ Alt Exh (MEG BUY) BOOK CD] $\rightarrow$ $\lambda \mathrm{A}\left[\operatorname{EXH}\left(\lambda \mathrm{w}_{2} \mathbf{b u y}\left(\mathrm{w}_{2}\right)(\mathrm{b} \oplus \mathrm{c})(\mathrm{m})\right]\left(\mathrm{A}_{0}\right) \Rightarrow\right.$ $\operatorname{EXH}\left(\lambda \mathrm{w}_{2} \mathbf{b u y}\left(\mathrm{w}_{2}\right)(\mathrm{b} \oplus \mathbf{c})(\mathrm{m})\right)\left(\mathrm{A}_{0}\right)$

[11] $\left[{ }_{V} e_{B E}\right] \leadsto \lambda \mathrm{p} \lambda \mathrm{q}_{<\mathrm{st}\rangle}[\mathrm{q}=\mathrm{p}]$

[12] $\left[{ }_{V^{\prime}} e_{B E}[(\right.$ MEG BUY) BOOK CD $]] \rightarrow$ $\lambda \mathrm{p} \lambda \mathrm{q}[\mathrm{q}=\mathrm{p}]\left(\operatorname{EXH}\left(\lambda \mathrm{w}_{2} \mathbf{b u y}\left(\mathrm{w}_{2}\right)(\mathrm{b} \oplus \mathrm{c})(\mathrm{m})\right)\left(\mathrm{A}_{0}\right)\right) \Rightarrow$ $\lambda \mathrm{q}\left[\mathrm{q}=\operatorname{EXH}\left(\lambda \mathrm{w}_{2} \mathbf{b u y}\left(\mathrm{w}_{2}\right)(\mathrm{b} \oplus \mathrm{c})(\mathrm{m})\right)\left(\mathrm{A}_{0}\right)\right]$

[13] $\left[{ }_{V P}\left[{ }_{C P} w A n s_{S T R O N G}\right.\right.$ MEG BUY WHAT $]\left[e_{B E}\left[_{I P}\right.\right.$ Alt Exh (MEG BUY) BOOK CD]] $\rightarrow$

$\lambda \mathrm{q}\left[\mathrm{q}=\operatorname{EXH}\left(\lambda \mathrm{w}_{2} \mathbf{b u y}\left(\mathrm{w}_{2}\right)(\mathrm{b} \oplus \mathrm{c})(\mathrm{m})\right)\left(\mathrm{A}_{0}\right)\right]\left(\operatorname{ANS}_{\mathrm{STRONG}}\left(\mathrm{w}_{0}\right)\left(\mathrm{Q}_{0}\right)\right) \Rightarrow$ $\operatorname{ANS}_{\text {STRONG }}\left(\mathrm{w}_{0}\right)\left(\mathrm{Q}_{0}\right)=\left[\operatorname{EXH}\left(\lambda \mathrm{w}_{2} \mathbf{b u y}\left(\mathrm{w}_{2}\right)(\mathrm{b} \oplus \mathrm{c})(\mathrm{m})\right)\left(\mathrm{A}_{0}\right)\right] \Rightarrow$ $\lambda \mathrm{w}_{1}\left[\operatorname{ANS}_{\mathrm{WEAK}}\left(\mathrm{w}_{0}\right)\left(\mathrm{Q}_{0}\right)=\operatorname{ANS}_{\mathrm{WEAK}}\left(\mathrm{w}_{1}\right)\left(\mathrm{Q}_{0}\right)\right]=$ $\lambda \mathrm{w}_{2}\left[\mathbf{b u y}\left(\mathrm{w}_{2}\right)(\mathrm{b} \oplus \mathrm{c})(\mathrm{m})=1 \wedge\right.$ $\forall \mathrm{q} \in \mathrm{A}_{0} \cdot\left[\mathrm{q}\left(\mathrm{w}_{2}\right)=1 \rightarrow\left[\left(\lambda \mathrm{w}_{2} \operatorname{buy}\left(\mathrm{w}_{2}\right)(\mathrm{b} \oplus \mathrm{c})(\mathrm{m}) \rightarrow \mathrm{q}\right)\right]\right]$ by (89) and (93)

\subsubsection{Non-exhaustive QACs}

The two operators $A$ S $_{\text {STRONG }}$ and Exh enforce the exhaustive interpretation of QACs by requiring that the two propositions which are equated by the silent copula are the strongly exhaustive true answer to the Q-constituent and the exhaustification of the Aconstituent with respect to one of its sub-constituents. However, there are also QACs that allow for a non-exhaustive/ "mention-some" interpretation, as was shown earlier (Sect. 4.3.1: ex. (80)). What triggers non-exhaustive interpretations of interrogative clauses in general is still an open issue, whose solution will crucially bear on a principled account of non-exhaustive QACs. We have found that non-exhaustive interpretations are taken to be a marked case, and seem to be triggered (or strongly facilitated) by modal contexts. Here we would like just to briefly sketch a possible approach to non-exhaustive QACs along the lines of our account for exhaustive QACs.

Our idea is that a different operator-one which is licensed by whatever characterizes non-exhaustive interrogatives in general-applies to the Q-constituent of QACs when they are interpreted non-exhaustively. Let's call it $A n s_{N O N-E X H}$. This operator applies to the set of propositions that the Q-constituent initially denotes and returns any true one, not necessarily the one entailing all the others. $A n s_{N O N-E X H}$ would therefore solve the type mismatch between the initial denotation of 
the Q-constituent and the relation of identity with the proposition denoted by the A-constituent, just like the answerhood operators we introduced earlier. On the other hand, $A n s_{N O N-E X H}$ would not enforce exhaustivity, since it would not necessarily return the exhaustive true answer. The restricted occurrence of non-exhaustive readings would translate into the restricted licensing conditions for $A n s_{N O N-E X H}$, which can be stated precisely only when the issue of the conditions under which non-exhaustive readings in general arise receives a better understanding. As for the non-exhaustive interpretation of the A-constituent, nothing special is needed since we already assumed that the operator Exh can occur optionally, once its licensing conditions are satisfied. When it does not apply and at the same time $A n s_{N O N-E X H}$ applies to the Q-constituent, a non-exhaustive reading of the QAC is generated.

Romero (2007) independently argues for $A n s_{N O N-E X H}$ (which she calls $A n s_{S O M E}$ ) by looking at the semantic behavior of two constructions: (i) NPs interpreted as concealed questions in the complement position of the equivalent of know in Spanish, and (ii) NPs in subject position of specificational copular sentences in Spanish. We refer the interested reader to this work for a precise formulation of the non-exhaustivity operator and further discussion.

\subsubsection{Polar QACs}

Recall that ASL also allows polar QACs, which have a polar interrogative as their Q-constituent and the answer particles YES or $N O$ as their A-constituent. An example is given in (103).

[Q-const MEG LAUGH], [A-const NO (MEG NOT LAUGH)]

'Meg was not laughing.'

Our semantic proposal can handle polar QACs as well. The syntactic structure for the QAC in (103) is given in (104) and its semantic analysis in (105) below. Comments follow.

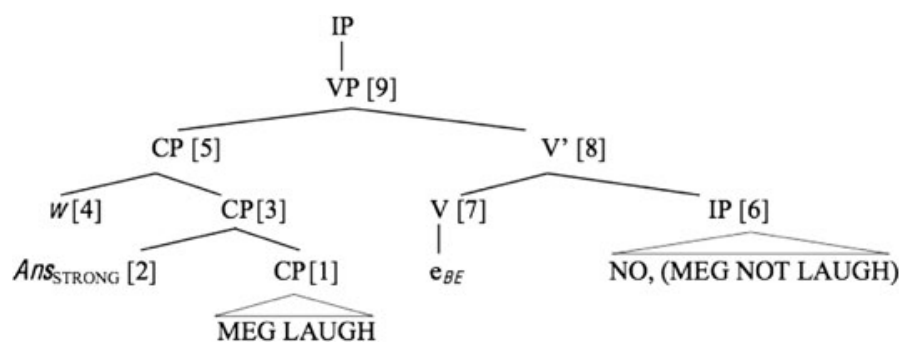

(105)

$$
\begin{aligned}
& {[1] \quad\left[{ }_{C P} \text { MEG LAUGH }\right] \sim \lambda \mathrm{w}_{1} \lambda \mathrm{p}\left[\mathrm{p}\left(\mathrm{w}_{1}\right)=1 \wedge\right.} \\
& \left.\left(\mathrm{p}=\lambda \mathrm{w}_{2} \operatorname{laugh}\left(\mathrm{w}_{2}\right)(\mathrm{m}) \vee \mathrm{p}=\lambda \mathrm{w}_{2} \neg \operatorname{laugh}\left(\mathrm{w}_{2}\right)(\mathrm{m})\right)\right] \Rightarrow_{\operatorname{def}} \mathrm{Q}_{0}
\end{aligned}
$$




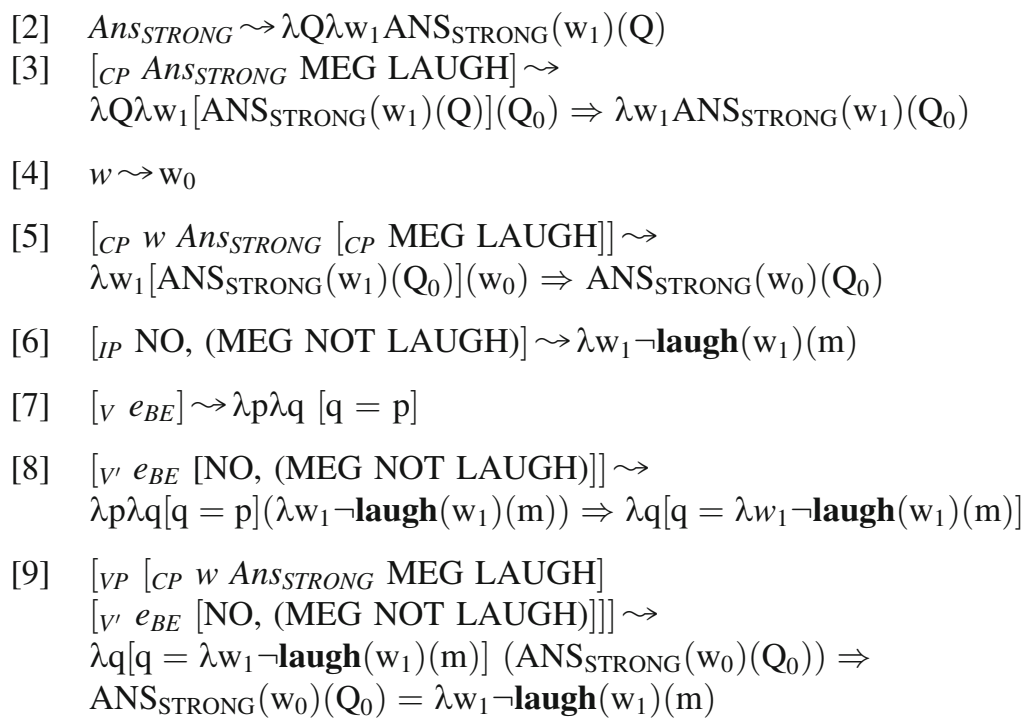

The denotation of the polar interrogative clause in the Q-constituent is the questionintension $\mathrm{Q}_{0}$. For each world, $\mathrm{Q}_{0}$ returns the singleton set containing just the true one of the two mutually exclusive answers to the question 'did Meg laugh?' (105: [1]). When $A n s_{\text {STRONG }}$ applies to $\mathrm{Q}_{0}$ in the world of evaluation $w_{0}$, it returns the only proposition in the singleton set $\mathrm{Q}_{0}\left(\mathrm{w}_{0}\right)$ (105:[5]).

As for the A-constituent, we assume that even when only the short answer $N O$ is signed, the A-constituent is syntactically and semantically the same as when the full answer NO (MEG NOT LAUGH) is signed. Since no phrase within the A-constituent is marked (everything can be silent), Exh is not licensed and the A-constituent just denotes what its IP denotes: a proposition. The objection may be raised that not everything is silent in the A-constituent; the answer particle $N O$ must be signed. It would not be difficult to define Exh such that it can range over answer particles or, better, polarity operators. But that would not change the final result, since there are only two mutually exclusive answer particles (in ASL) and polarities (in natural languages).

\subsubsection{QACs with a quantificational phrase as the A-constituent}

The semantics of interrogatives that we are adopting, based on Hamblin (1973), Karttunen (1977), and subsequent work, faces a problem in dealing with non-referential/quantificational answers to constituent interrogatives, as discussed in Spector (2008). For QACs, this means that our semantic analysis does not derive the correct truth conditions if the A-constituent is a quantificational phrase, like EVERYTHING in (106), or contains a quantificational phrase as the marked constituent, like NO-ONE in (107).

'John bought everything.' 
(107) [Q-const WHO CAME], [A-const NO-ONE (CAME)]

'No one came.'

Spector (2008) suggests an amendment to Karttunen (1977) in which variables over generalized quantifiers are introduced. Though he motivates his proposal with a different set of problematic facts, it can be used to handle our problem as well. We refer the interested reader to Spector (2008) for details.

\subsection{Conclusions about the semantic analysis}

In this section, we have developed an analysis for QACs that syntactically treats them as a copular construction with a silent copula connecting an interrogative clause (the Q-constituent) with a declarative clause (the A-constituent). Semantically, a QAC conveys the proposition that is true in all the worlds in which the proposition denoted by the Q-constituent and the one denoted by the A-constituent are the same. The Q-constituent ends up denoting a proposition via answerhood operators applying to the question-intension and returning the strongly exhaustive answer (as the default) or a partial/non-exhaustive answer (in a few restricted cases). The A-constituent denotes the proposition returned by an exhaustivity operator triggering exhaustification with respect to the marked sub-constituent (i.e., the subconstituent that can never be left unsigned).

Besides providing a detailed complete account of QACs semantic properties, we believe our analysis also provides further independent evidence supporting the need for answerhood operators and for the exhaustivity operator in the grammar.

\section{On the pragmatics of QACs}

In this section, we first discuss differences in the conditions of use between a QAC and the truth-conditionally equivalent simple declarative clause (henceforth non$Q A C$ ), and then suggest an account based on the approach to discourse-structuring known as the Question Under Discussion theory.

\subsection{Pragmatic puzzles}

At the beginning of a discourse, or " out of the blue", a QAC is much less preferred than the corresponding non-QAC:

(108) Scenario: At the beginning of a story ("Once upon the time ...'):

a. \# MAN BUY WHAT, BOOK. (QAC)

'The thing/What a man bought is a book.'

b. MAN BUY BOOK.

(non- $Q A C)$

'A man bought a book.' 
Another instance in which the QAC is infelicitous, while the non-QAC is fully acceptable, is the case in which the Q-consistent of the QAC repeats an interrogative clause that has just been signed (and the A-constituent answers it):

(109) Scenario: Signer A just asked 'What did John buy?' and Signer B replies:
a. \# JOHN BUY WHAT, BOOK.
'The thing/What John bought is a book.'
b. JOHN BUY BOOK.
'John bought a book.'
$(Q A C)$
(non- $Q A C)$

However, a QAC is felicitous if the Q-constituent conveys a question related to the main question that has been previously raised. Therefore, the A-constituent conveys an answer that looks like a partial answer to the main question. For instance, if Signer A raises the main question in (110a) about Signer B's shopping activity yesterday, then Signer B can felicitously use the QAC in (110b) to answer the related question about what Signer B bought in her shopping. Unsurprisingly, the corresponding non-QAC in (110c) is felicitous as well.
(110) a. Signer A: YESTERDAY YOU BUY-BUY?
'Were you shopping yesterday?'
b. Signer B: I BUY WHAT, BOOK.
'The thing/What I bought is a book.'
c. Signer B: BOOK, I BUY. / I BUY BOOK. ${ }^{20}$
'I bought a book.'

$(Q A C)$

(non-QAC)

Notice that the question raised in the Q-constituent of the QAC in (110b) is only one of many questions related to the main question in (110a). Other related questions could ask about where the shopping occurred, for how long, with whom, etc.

Finally, the contrast between the use of a QAC and the corresponding non-QAC returns if the QAC and the non-QAC are used to form a polar interrogative. In (111a), a QAC is signed with the typical non-manual marking of a polar interrogative across the entire sentence (brow raise); this is completely unacceptable. Meanwhile, the corresponding non-QAC is a well-formed polar interrogative, as shown in (111b).

a.

*JOHN BUY WHAT, BOOK.

('The thing/What John bought is a book.') ( $Q A C)$

b. $b r$

JOHN BUY BOOK?

'Did John buy a book?'

In fact, a QAC can never be interpreted as a polar interrogative.

\footnotetext{
${ }^{20}$ The non-QAC with the object $B O O K$ in initial position is the most natural way to answer the question, though our consultants also accepted the non-QAC with $B O O K$ in final position, which exhibits the "standard" SVO word order in ASL.
} 
The pattern above suggests that a QAC may require background information to be associated with it, unlike the corresponding non-QAC. In particular, our data supports Wilbur's suggestion that the Q-constituent typically conveys old, backgrounded information, while the A-constituent conveys new, foregrounded information (Wilbur 1994). One way to characterize this pragmatic behavior of QACs is in terms of its function in overtly communicating aspects of the discourse structure. In what follows, we suggest that QACs are used to signal the (sub-)topic under discussion (by means of the question conveyed by the Q-constituent) and the related new information that is introduced in the discourse (by means of the answer conveyed by the A-constituent). First, though, we need to briefly introduce the theory of discourse that we are adopting.

\subsection{Question Under Discussion theory}

The Question Under Discussion (QUD) theory is a theory of discourse proposed by Roberts (1998). Its core idea is that discourse can be modeled as a series of questions and answers, and that utterances are made in response to either explicit or implicit questions. Its primary motivation is an account of focus patterns. Focus has long been associated with questions, because of the correspondence between the syntactic role of a wh-phrase in a constituent interrogative clause conveying a question and the syntactic role of the constituent carrying focus in the declarative clause that is an appropriate answer to that question. For instance, the wh-word who in the interrogative clause in (112a) acts as the subject, and the placement of the focus in its answer is on the subject nominal $J O H N$, as shown in (112b). If the syntactic role of the wh-phrase and the focus placement do not match, the answer is infelicitous, as shown in (113a-b).

(112) a. Speaker A: Who bought pasta?

b. Speaker B: JOHN bought pasta.

(113) a. Speaker A: Who bought pasta?

b. Speaker B: \#John bought PASTA.

In the QUD framework, focus is accounted for through a requirement of questionanswer congruence, which demands that focus must correspond to the question constituent in an interrogative clause. When a question has not explicitly been introduced into the discourse, the focus is instead answering an implicit QUD. An example of focus corresponding to an implicit QUD is in (114).

(114) Scenario: Participants in a conversation are attempting to discover the identity of the person who bought the pasta. Therefore, the implicit main question/issue that is raised is: 'Who bought pasta?'

a. JOHN bought pasta.
b. \#John bought PASTA.

Büring (2003) extends the QUD framework beyond primary focus accents to an analysis of contrastive topic accents. An example of contrastive topic accenting can 
be seen in (115). In this example, it is clear that the explicit QUD, Who bought what? is not fully answered by the declarative sentence uttered by Speaker B. Instead, Speaker B signals to Speaker A that he is only partially answering the QUD with the rising intonation on John.

Speaker A: Who bought what?

Speaker B: JOHN (rising intonation) bought PASTA.

Büring (2003) suggests that the contrastive topic accent instantiates the discourse structure seen in (116), comprised of a main QUD, sub-QUDS, and answers. The answers are sometimes complete and directly reply to the QUD, and are at other times incomplete/partial and address only sub-QUDs. When they are incomplete/ partial, this is signaled using a contrastive topic accent. Contrastive topic accents are also sometimes known as B-accents, as opposed to A-accents, which indicate primary focus, noted in (116e).

(116) a. Main QUD: Who bought what?

b. Sub-QUD 1: What did John bring?

c. Sub-QUD 2: What did Meg bring?

d. Sub-QUD 3: What did Kyle bring?

e. Answer to Sub-QUD 1: $\operatorname{JOHN}_{[B \text {-accent }]}$ bought PASTA $[A$-accent $]$.

In sum, the occurrence of just primary focus/A-accents signals a direct answer to a QUD, while the co-occurrence of contrastive topics/B-accents along with focus/ A-accents signals an answer to a sub-question of a QUD. In a case where there is no specific QUD, such as a statement made "out of the blue"' or at the beginning of a story, sentences resort to the default stress pattern of the language. As shorthand, we will sometimes refer to this as having a lack of A-accent or B-accent focus.

\subsection{Proposal: The pragmatic function of QACs}

Returning to QACs in ASL, it has often been mentioned that they seem to place in focus the A-constituent (Petronio 1991; Wilbur 1994, 1996; Petronio and LilloMartin 1997). Under this view, $B O O K$ in the ASL sentence in (117) serves a similar purpose to the emphasized/focused $B O O K$ in the English sentence in (118): they both convey new information and signal the locus of the exhaustification.

(117) JOHN BUY WHAT, BOOK.

'What John bought is a book.'

(118) John bought a BOOK.

Our proposal is that QACs are associated to a very precise pragmatic function: they are a device by means of which ASL allows the signer to both make an implicit sub-QUD explicit (by the Q-constituent) and answer it (by the A-constituent). And they do so by means of just one sentence that combines the overt sub-QUD with its answer. 
We can now suggest a way to approach the contrasts and the similarities in the pragmatic patterning of the QACs and the non-QACs we started with in Sect. 5.1. First, if the Q-constituent of a QAC and its non-manual marking (brow raising) explicitly signal that the question conveyed is a sub-QUD, then it follows that QACs cannot be uttered out of the blue without an existing main QUD. It may help to think about the A-accent (primary focus) and B-accent (contrastive topic) placement pattern in English that we mentioned above. For instance, the English sentence in (119) cannot be uttered out of the blue with the marked intonational pattern.

(119) \#Once upon a time, a WOMAN ${ }_{[B \text {-accent }]}$ bought a HANDBAG $\operatorname{HA}_{[\text {-accent }]}$.

Second, QACs cannot be used to give a direct complete answer to the main QUD for very similar reasons: it goes against their intrinsic nature of highlighting an implicit sub-QUD. QACs parallel the A-accent and B-accent pattern in English. Speaker B in (120) cannot reply to Speaker A's broad question with the marked intonational pattern.

Speaker $A$ : What happened?

Speaker B: \# MARY $[$ B-accent $]$ bought a HANDBAG ${ }_{[A \text {-accent }]}$.

QACs pattern like non-QACs when they are used to highlight an implicit subQUD since this fits their pragmatic function. On the other hand, QACs cannot be used to form a polar question because it goes against their requirement of highlighting an implicit sub-QUD and, crucially, answering it. Similarly, our intuition is that the A-accent and B-accent pattern in English cannot be used to convey a polar question:

$$
\text { \#Are you really sure? } \operatorname{MARY}_{[B \text {-accent }]} \text { bought a } \mathrm{HANDBAG}_{[A \text {-accent }]} \text { ? }
$$

Our proposal about the pragmatic function that is associated with QACs can also shed light on two other properties that QACs exhibit. First, the Q-constituent cannot repeat a question that was already signed explicitly, even if it is a subQUD and not the main QUD. For instance, the dialogue in (122) is addressing the main QUD: "What did each person buy?', Signer A overtly signs a related subQUD, but Speaker B cannot sign a QAC whose Q-constituent repeats the very same sub-QUD that Signer A just signed. This is because the sub-QUD is no longer implicit, which is one of the pragmatic requirements that QACs impose for their use.

(122) Scenario: The main QUD is: 'What did each person buy?'

Signer A: JOHN BOUGHT WHAT?

'What did John buy?'

Signer B: \# JOHN BUY WHAT, BOOK.

'The thing/What John bought is a book.' 
Once again, the very same restriction is observed with the distribution of the A-accent and B-accent in English:

(123) Scenario: The main QUD is: What did each person buy?

Speaker A: What did John buy?

Speaker B: \#JOHN $\mathrm{JB}_{[\text {-accent }]}$ bought a $\mathrm{HANDBAG}_{[A \text {-accent }]} \cdot{ }^{21}$

Finally, the order between the Q-constituent and the A-constituent is fixed: the Q-constituent always precedes the A-constituent; the reverse order is completely unacceptable. Why would this be? If the pragmatic function of a QAC is to highlight an implicit sub-QUD and then answer it, the constituent that highlights the sub-QUD has to be signed first. This could be part of a more general pragmatic constraint on discourse building that prevents raising a question right after having answered it.

To conclude, we have suggested that QACs have a very specific pragmatic function: they allow the very same signer to both highlight an implicit sub-QUD and answer it. We are aware that this is not a fully principled explanation of why this is the case. Still, we believe we have contributed to a unified description of several different puzzling properties and restrictions of QACs and, crucially, we have highlighted the close parallelism with a phenomenon that looks very different on the surface: the A-accent and B-accent placement pattern in English. In particular, the pragmatic function of the Q-constituent in a QAC in ASL turns out to be the same as the pragmatic function of the B-accent in a declarative clause in English: they both unequivocally signal the sub-QUD that the speaker/signer is addressing. The A-constituent signals that it delivers new information provided as an answer to a (sub-)QUD, similarly to the A-accent in English. If correct, our pragmatic analysis brings explicit support to an approach of analyzing discourse structure along the line of the Question Under Discussion theory.

\section{QACs are not pseudoclefts}

The semantic analysis that we provided for QACs in Sect. 4 closely resembles a popular approach to specificational pseudoclefts, developed in different ways by Ross (1972), den Dikken et al. (2000), and Schlenker (2003), among others. According to this approach, the specificational pseudocleft in (124) is analyzed as syntactically and/or semantically equivalent to the structure in (125). The precopular wh-clause is analyzed as a CP conveying a question, while the postcopular constituent is analyzed as a (partially elided) IP conveying the answer to the question. As in our analysis of QACs, the two parts of the specificational pseudocleft are connected by the copula. ${ }^{22}$

\footnotetext{
${ }^{21}$ Our consultants judge Speaker B's utterance as infelicitous in the following relevant situation. First, the main QUD is raised overtly or implicitly. Then the discourse develops in various directions and different kinds of sub-QUDs are raised. Finally, Speaker A utters her question, crucially, without stress on the subject (John). Thanks to Christine Bartels for feedback that triggered this clarification.

22 For a different approach, according to which specificational pseudoclefts are an equation between the precopular and postcopular phrases as they appear on the surface, see Jacobson (1994), Sharvit (1999), Cecchetto (2000, 2001), Heller (2002), and Caponigro and Heller (2007), a.o.
} 
(124) What we saw in LA was Les plages d'Agnès.

(125) [CP What we saw in LA] was [IP (we saw) Les plages d'Agnès].

Grolla (2004) explicitly suggests that this analysis of specificational pseudoclefts should be extended to QACs as well. However, our data argue for differentiation between these two constructions based on both semantic and syntactic properties.

One of the most striking differences between QACs in ASL and pseudoclefts in other languages comes from the distribution of wh-words. As we showed in Sect. 3.1, the Q-constituent of a QAC allows any wh-word, including manner and purpose wh-words (WHY, HOW), as shown in (129) for $H O W$, D-linked wh-words $(W H I C H)$, as shown in (130), or amount wh-words (HOW-MUCH), as shown in (131). In fact, QACs use exactly the same wide range of wh-words that are used in wh-questions in ASL. This contrasts with specificational pseudoclefts, which crosslinguistically are always introduced by a proper subset of the wh-words that introduce interrogatives (Caponigro and Heller 2007). For example, English has whwords like how, which, and how much, but none appear in specificational pseudoclefts; cf. (126)-(128). On the other hand, the ASL equivalents of those wh-words are perfectly fine in QACs; cf. (129)-(131).

(126) *How he drove here was really fast.

(127) *Which book John bought was that one.

(128) *How much the car cost was $\$ 20,000$.

(129) JOHN DRIVE HOW, VERY-FAST

'John drove really fast.'

(130) JOHN BUY BOOK WHICH, THAT

'The book John bought was that one.'

(131) CAR COST HOW-MUCH, \$20,000

'The car cost $\$ 20,000$.'

Besides differences in the wh-words that are used in specificational pseudoclefts and in QACs, there is also an important difference with respect to other uses of wh-words. Caponigro and Heller (2007) note that languages with pseudoclefts also allow free relatives in non-pseudocleft constructions, as shown by the free relative in the complement position of the matrix predicate bought in (132). In contrast, as we mentioned earlier and illustrate again in (133), relative constructions using wh-words in ASL are reported as ungrammatical or feeling like a signed version of English (Liddell 1978).

(132) I bought [what John bought].

(133) *I BUY [WHAT JOHN BUY]. 
There are also differences between the A-constituent in a QAC and what would be the corresponding part of a pseudocleft. For example, the A-constituent may be a full IP in a QAC ((134)) while in English, a full sentential A-constituent is degraded ((135)). The English example may be improved, especially in sentences of the form discussed in Ross (1972), such as (136), although as far as we can tell this improvement appears to be an exception, not the rule; cf. (137).

(134) JOHN BUY WHAT, [HE BUY BOOK].

'What John bought is a book.'

(135) ?What John bought is [he bought a book].

(136) What John did is [he went to the store].

(137) ?Where John went was [he went to the store].

The usage of a full IP in QACs seems to depend mostly on discourse conditions, since usually there is no need to include the non-focused part of the IP. While this constraint may also exist for English pseudoclefts, there seem to be further constraints in English that are based entirely on syntactic and lexical variation such that only a few select types of pseudoclefts are truly natural with a full IP following the wh-phrase. This is also further evidence that the QAC is closer to a question-answer pair than a pseudocleft is, since a matrix question-answer pair may have a full IP answer both in ASL and in English, as seen in (138) and (139), respectively.

\section{Signer A: JOHN BUY WHAT? \\ 'What did John buy?'}

Signer B: HE BUY BOOK

'He bought a book'.

(139) Speaker $A$ : What did John buy?

Speaker B: He bought a book.

Another unaccounted-for difference between QACs and pseudoclefts is that pseudoclefts may generally (although not always) reverse the order of their constituents and remain grammatical, as seen in (140) and (141), while the corresponding sentences in ASL are nonsensical, as seen in (142) and (143).

(140) a. [What John bought] is [a book].

b. [A book] is [what John bought].

(141) a. [Where we should go] is [Puerto Rico].

b. [Puerto Rico] is [where we should go].

(142) a. [JOHN BUY WHAT], [BOOK].

'The thing/What John bought is a book.'

b. $*[\mathrm{BOOK}],[\mathrm{JOHN}$ BUY WHAT]. 
(143) a. [SHOULD GO WHERE], [PUERTO RICO].

'The place/Where we should go is Puerto Rico.'

b. *[PUERTO RICO], [SHOULD GO WHERE].

Here, too, the QAC behaves more like a question-answer pair than the pseudocleft does, since answers obviously follow their questions in discourse. We should note that while not all theories consider pseudoclefts with the wh-clause in initial position to be the same structurally as those with the wh-clause in final position (den Dikken et al. 2000), we mention the difference here because this is an asymmetry that is failed to be explained by previous accounts that treat QACs and pseudoclefts as equivalent.

QACs also allow for a polar interrogative in the Q-constituent, as in (144) and (145), something that is clearly ungrammatical in specificational pseudoclefts, as seen in (146) and (147).

(144) [I LAUGH], [NO].

'I did not laugh.'

(145) [JOHN BUY BOOK], [YES].

'John bought a book.'

(146) *[Whether John bought a book] is [no/he didn't].

(147) *[Should John get a car] is [yes/he should].

Here, again, QACs pattern with discourse level question-answer pairs, while pseudoclefts do not.

We mention two last differences which are semantic in nature, and for which judgments are more variable, but which exhibit a contrast in acceptability. The first is the naturalness of a non-referential answer in the A-constituent. Such answers are reported by our consultants to be very natural in QACs in ASL, such as (148) and (149). This assessment contrasts with the variability of judgments given to the corresponding pseudoclefts, as shown in (150) and (151).

(148) JOHN BUY WHAT, (HE BUY) NOTHING.

'John bought nothing.'

(149) JOHN GO WHERE, (HE GO) EVERYWHERE.

'John went everywhere.'

(150) ?What John bought is nothing.

1. Predicational reading:

The things that John bought are (worth) nothing.

2. Specificational reading

??John did not buy anything. 
(151) ?Where John is going is everywhere.

1. Predicational reading:

The place/places John is going is/are everywhere.

2. Specificational reading:

??John is going to every place.

We suggest that the source of the variability in English speakers' judgments may be due to the availability of predicational readings for pseudoclefts, which seem to be more available than specificational readings. What is important is that this differs from non-referential A-constituents in QACs, which seem to be fully felicitous in all scenarios. This is also another way in which, unlike specificational pseudoclefts, QACs behave like question-answer pairs in ASL (152) and in English (153).

\section{Signer A: JOHN BUY WHAT? \\ 'What did John buy?' \\ Signer B: NOTHING. \\ 'Nothing'.}

Speaker A: What did John buy?

Speaker B: Nothing.

The final asymmetry between QACs and pseudoclefts is their behavior regarding exhaustivity. While the default interpretation for both seems to be an exhaustive reading, some QACs allow for a non-exhaustive reading, as discussed in Sect. 4.3 and shown again in (154) below. As mentioned, the same pattern is observed in the corresponding discourse-level question-answer pairs in both ASL and English. On the other hand, the corresponding specificational pseudoclefts strongly prefer an exhaustive reading, independent of context. (155) sounds awkward because it is interpreted as asserting that the only contextually relevant place where you can buy coffee is Starbucks, while the context makes it clear that Starbucks is only one of the contextually relevant coffee places.

(154) Scenario: There are multiple places nearby to buy coffee.

CAN BUY COFFEE WHERE, STARBUCKS.

'You can buy coffee at Starbucks.'

(155) ? Where you can buy coffee is Starbucks.

To review, we find the evidence discussed in this section to show that, although they may sometimes be used for similar discourse functions, QACs in ASL exhibit several syntactic and semantic differences with respect to specificational pseudoclefts, and they should henceforth be considered as two separate constructions. Moreover, every time they differ, QACs, but not pseudoclefts, behave more like question-answer pairs. This brings further support to our analysis of QACs as combining an interrogative clause conveying a question with the declarative clause conveying the answer to that question. 


\section{Conclusions}

In this paper, we have argued that QACs in ASL are an interesting object of investigation in their own right as well as for the light that they shed on various aspects of the syntax/semantics/pragmatics interface. We have given a syntactic and semantic analysis of QACs according to which they are a declarative clause formed by an interrogative CP (the Q-constituent) and a declarative IP (the A-constituent), both denoting a proposition. These two constituents occur as the subject and the object of a silent copular predicate that semantically behaves like an identity relation. Our analysis captures the exhaustive reading of (typical) QACs by means of answerhood and exhaustivity operators that have been independently argued for in the literature (Heim 1994; Chierchia et al. 2009, to appear), providing further support for their existence in the grammar. We have also briefly suggested a possible way to address non-exhaustive readings of QACs, although a satisfactory solution of this issue requires a better understanding of non-exhaustive readings of interrogative clauses in general.

We have discussed several pragmatic properties of QACs and suggested an account according to which QACs represent an overt instantiation of a sub-question under discussion and the answer to it. We have also highlighted the very close similarity between the pragmatic properties of QACs and the A-accent and B-accent placement pattern in English. Our pragmatic proposal is framed within the Question Under Discussion theory (Roberts 1998; Büring 2003) and, if correct, brings further evidence to this approach to discourse structuring.

Finally, we have compared QACs with specificational pseudoclefts in English and other languages, since QACs have been argued to be pseudoclefts (Petronio 1991; Wilbur 1994, 1996; Grolla 2004) and specificational pseudoclefts have received a very similar analysis to the one that we have suggested for QACs (Ross 1972; den Dikken et al 2000; Schlenker 2003). We have discussed several important differences between the two constructions and have noted that whenever QACs differ from specificational pseudoclefts, discourse-level question-answer pairs pattern like QACs rather than specificational pseudoclefts.

QACs, therefore, show that question-answer pairs, although usually discourselevel units, can occur as a syntactic and semantic unit as well. The natural expectation is that QACs may occur in other languages, although we already know that many languages we are familiar with lack QACs. Further investigation is needed to understand what factors determine the presence or absence of QACs in a given language. In this paper, we have suggested a series of analytical tools that can be used for such an investigation.

Acknowledgements We extend our deepest thanks to Brandon Scates, Frank Gallimore, Jamie Gould, and other consultants who wish to remain anonymous for sharing their language with us. We warmly thank and acknowledge Rachel Mayberry for her continuous support and substantial contribution to the development of this work. Special thanks to Veneeta Dayal, Donka Farkas, and two anonymous reviewers for very helpful detailed comments and suggestions. We also extend our thanks to Christine Bartels Gennaro Chierchia, Paul Elbourne, Carlo Geraci, Anastasia Giannakidou, Andreas Haida, Matt Hall, Andrew Kehler, Diane Lillo-Martin, Matt Pearson, Carson Schütze, Yael Sharvit, as well as audiences at CLS 44, SALT 18, WCCFL 27, MIT Ling-Lunch, the UCLA Linguistics Department Colloquium, and 
the UMD Linguistics Department Colloquium for their helpful suggestions. Finally, we are grateful to Carol Neidle for permission to use the NCSLGR SignStream database images. The authors' names are in alphabetical order. Both authors are equally responsible for every part of the paper, and are the only ones responsible for any remaining mistake.

Open Access This article is distributed under the terms of the Creative Commons Attribution Noncommercial License which permits any noncommercial use, distribution, and reproduction in any medium, provided the original author(s) and source are credited.

\section{References}

American Sign Language Linguistic Research Project. 2007. Maintained by the National Center for Sign Language and Gesture Resources Signstream Database. Boston University: CD-ROM.

Baker-Shenk, C.L. 1983. A microanalysis of the non-manual components of questions in American Sign Language. $\mathrm{PhD}$ thesis, University of California, Berkeley.

Beck, S., and H. Rullmann. 1999. A flexible approach to exhaustivity in questions. Natural Language Semantics 7: 249-298.

Büring, D. 2003. On D-trees, beans, and B-accents. Linguistics and Philosophy 26: 511-545.

Caponigro, I., and D. Heller. 2007. The non-concealed nature of free relatives: Implications for connectivity in specificational sentences. In Direct compositionality, ed. C. Barker and P. Jacobson, 237-263. Oxford, UK: Oxford University Press.

Caponigro, I., and J. Sprouse. 2007. Rhetorical questions as questions. In Proceedings of Sinn und Bedeutung 11, ed. P. Waldmuller, 121-133. Barcelona: Universitat Pompeu Fabra.

Cecchetto, C. 2000. Connectivity and anti-connectivity in pseudoclefts. In Proceedings of NELS 30, ed. M. Hirotani, A. Coetzee, N. Hall, and J. Kim, 137-151. Amherst: GLSA.

Cecchetto, C. 2001. Syntactic or semantic reconstruction? Evidence from pseudoclefts and clitic left dislocation. In Semantic interfaces, ed. C. Cecchetto, G. Chierchia, and M.T. Guasti, 90-144. Stanford: CSLI Publications.

Chierchia, G. 2004. Scalar implicatures, polarity phenomena, and the syntax/pragmatics interface. In Structures and beyond. The cartography of syntactic structures, ed. A. Belletti, Vol. 3, 39-103. Oxford, UK: Oxford University Press.

Chierchia, G., D. Fox, and B. Spector. 2009. Hurford's constraint and the theory of scalar implicatures. In Presuppositions and implicatures, ed. P. Egré and G. Magri, Vol. 60, 47-62. MIT Working Papers in Linguistics. Cambridge, MA: MIT.

Chierchia, G., D. Fox, and B. Spector. To appear. The grammatical view of scalar implicatures and the relationship between semantics and pragmatics. In An international handbook of natural language meaning, ed. P. Portner. The Hague: de Gruyter.

Dayal, V. 1996. Locality in WH quantification: Questions in relative clauses in Hindi. Dordrecht: Kluwer. den Dikken, M., A. Meinunger, and C. Wilder. 2000. Pseudoclefts and ellipsis. Studia Linguistica 54: 4189.

Groenendijk, J., and M. Stokhof. 1982. Semantic analysis of wh-complements. Linguistics and Philosophy 5: 175-233.

Groenendijk, J., and M. Stokhof. 1984. Studies on the semantics of questions and the pragmatics of answers. PhD thesis, University of Amsterdam.

Groenendijk, J., and M. Stokhof. 1994. Questions. In Handbook of logic and language, ed. J. van Benthem J and A. ter Meulen, 1055-1124. Amsterdam: Elsevier Science.

Grolla, E. 2004. Clausal equations in American Sign Language: A semantic analysis. Manuscript based on poster presented at Theoretical Issues in Sign Language Research 8, University of Connecticut.

Guerzoni, E., and Y. Sharvit. 2007. A question of strength: On NPIs in interrogative clauses. Linguistics and Philosophy 30: 361-391.

Gunlogson, C. 2003. True to form: Rising and falling declaratives as questions in English. New York: Routledge.

Hamblin, C. 1973. Questions in Moutage English. Foundations of Language 10: 41-53.

Heim, I. 1994. Interrogative semantics and Karttunen's semantics for 'know'. In Proceedings of IATL 1, ed. R. Buchalla and A. Mittwoch, 128-144. Jeusalem: Akademon.

Heller, D. 2002. On the relation of connectivity and specificational pseudoclefts. Natural Language Semantics 10: 243-284. 
Hoza, J., C. Neidle, D. MacLaughlin, J. Kegl, and B. Bahan. 1997. A unified syntactic account of rhetorical questions in American Sign Language. In Syntactic structure and discourse function: An examination of two constructions in American Sign Language, ed. C. Neidle, D. MacLaughlin, and R. Lee, Vol. 4, 1-23. American Sign Language Linguistic Research Project Report. Boston University, http://www.bu.edu/asllrp/index.html.

Jacobson, P. 1994. Binding connectivity in copular sentences. In Proceedings of SALT 4, ed. M. Harvey and L. Santelmann, 161-178. Ithaca, NY: CLC Publications.

Karttunen, L. 1977. Syntax and semantics of questions. Linguistics and Philosophy 1: 3-44.

Klima, E., and U. Bellugi. 1979. The signs of language. Cambridge, MA: Harvard University Press.

Krifka, M. 1993. Focus and presupposition in dynamic interpretation. Journal of Semantics 10: 269-300.

Lahiri, U. 2002. Questions and answers in embedded contexts. Oxford, UK: Oxford University Press.

Liddell, S.K. 1978. Non-manual signals and relative clauses in American Sign Language. In Understanding language through sign language research, ed. P. Siple, 59-90. New York: Academic Press.

Link, G. 1983. The logical analysis of plurals and mass terms. In Meaning, use, and interpretation of language, ed. R. Bauerle, C. Schwarze, and A. von Stechow, 302-323. The Hague: de Gruyter.

Lipták, A. (ed.). 2009. Correlatives cross-linguistically. Amsterdam: Benjamins.

Neidle, C., J. Kegl, D. MacLaughlin, B. Bahan, and R.G. Lee. 2000. The syntax of American Sign Language: Functional categories and hierarchical structure. Cambridge, MA: MIT Press.

Padden, C. 1988. Interaction of morphology and syntax in American Sign Language. Outstanding Dissertations in Linguistics. New York: Garland.

Petronio, K. 1991. A focus position in ASL. In Proceedings of the Third Student Conference in Linguistics, ed. J. Bobaljik and T. Bures, Vol. 14, 211-225. MIT Working Papers in Linguistics. Cambridge, MA: MIT.

Petronio, K., and D. Lillo-Martin. 1997. Wh-movement and the position of Spec-CP: Evidence from American Sign Language. Language 73: 18-57.

Roberts, C. 1998. Information structure in discourse: Towards an integrated formal theory of pragmatics. Columbus: Ohio State Working Papers in Linguistics.

Romero, M. 2007. Connectivity in a unified analysis of specificational subjects and concealed questions. In Direct compositionality, ed. C. Barker and P. Jacobson, 264-305. Oxford: Oxford University Press.

Rooth, M. 1992. A theory of focus interpretation. Natural Language Semantics 1: 117-121.

Ross, J. 1972. Act. In Semantics of natural language, ed. D. Davidson and G. Harman, 70-126. Dordrecht: Reidel.

Sandler, W., and D. Lillo-Martin. 2006. Sign language and linguistic universals. Cambridge, UK: Cambridge University Press.

Schlenker, P. 2003. Clausal equations: A note on the connectivity problem. Natural Language and Linguistic Theory 21: 157-214.

Sharvit, Y. 1999. Connectivity in specificational sentences. Natural Language Semantics 7: 299-304.

Spector, B. 2008. An unnoticed reading for wh-questions: Elided answers and weak islands. Linguistic Inquiry 39: 677-686.

Stokoe, W., D. Casterline, and C. Cronenberg. 1976. A dictionary of American Sign Language on linguistic principles. Silver Spring, MD: Linstok Press.

Wilbur, R.B. 1994. Foregrounding structures in American Sign Language. Journal of Pragmatics 22: 647-672.

Wilbur, R.B. 1996. Evidence for the function and structure of wh-clefts in American Sign Language. International Review of Sign Linguistics 2: 209-256.

Wilbur, R.B. 1999. Stress in ASL: Empirical evidence and linguistic issues. Language and Speech 2: 229-350. 